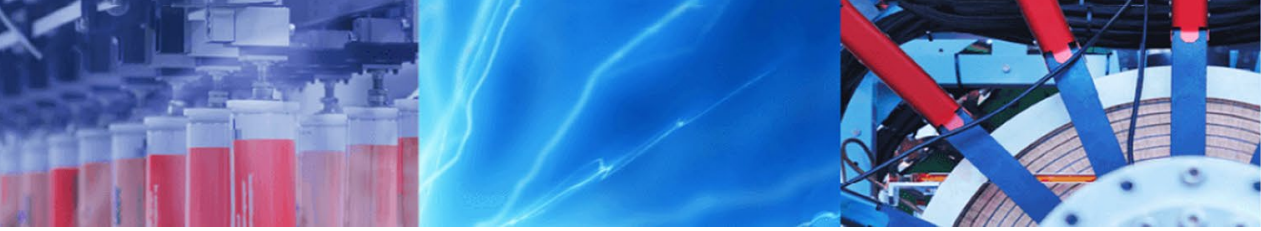

Research Article

\title{
Development of sustainable acid blue 113 dye adsorption system using nutraceutical industrial Tribulus terrestris spent
}

\author{
Mohammed A. H. Dhaif Allah ${ }^{1,2} \cdot$ Syed Noeman Taqui ${ }^{3} \cdot$ Usman Taqui Syed $^{4} \cdot$ Akheel Ahmed Syed $^{5}$
}

(c) Springer Nature Switzerland AG 2019

\begin{abstract}
First-ever study was done using a low-cost Tribulus terrestris spent, a by-product of a nutraceutical industry as an effective biosorbent for removing acid blue 113 (AB113) from aqueous media. The effect of various factors such as $\mathrm{pH}$, dye concentration, amount of adsorbent, particle size of adsorbent, contact time as also temperature on adsorption have been studied. Analysis of equilibrium data was done by using two number of two-parameter and six number of threeparameter isotherm models. Kinetic studies on adsorption were done using models like pseudo-first order and pseudosecond order. Webber-Morris and Dumwald-Wagner diffusion models helped to study diffusion. Determination and evaluation were also done for change in enthalpy $\left(\Delta \mathrm{H}^{\circ}\right)$, entropy $\left(\Delta \mathrm{S}^{\circ}\right)$, and Gibbs free energy $\left(\Delta \mathrm{G}^{\circ}\right)$ of adsorption system. Scanning electron microscopy, Fourier transform infrared spectroscopy and determination of point of zero-charge were carried out for surface characterization of the adsorbent. We have used a two-level fractional factorial experimental design approach and subsequently analysis of variance to define a statistically developed model from which we obtained values of above parameters which yielded maximum possible adsorption as $93.00 \mathrm{mg} / \mathrm{g}$. The investigations proved that nutraceutical industrial $T$. terrestris spent is both cost-effective and an efficient biosorbent for the remediation of $A B 113$ dye from aqueous system and textile industrial effluent.
\end{abstract}

Keywords Acid blue 113 · Adsorption studies · Isotherms · Nutraceutical industrial spent · Nutraceutical industrial Tribulus terrestris spent $\cdot$ Fractional factorial experimental design $\cdot$ ANOVA

$\begin{array}{ll}\text { Abbreviations } \\ \text { NIS } & \text { Nutraceutical industrial spent } \\ \text { NITTS } & \text { Nutraceutical industrial Tribulus terrestris } \\ \text { AB113 } & \text { Acid blue } 113 \\ \text { FTIR } & \text { Fourier transform infrared spectroscopy } \\ \text { SEM } & \text { Scanning electron microscopy } \\ q_{t} & \text { Adsorption capacity at time' } \mathrm{t}^{\prime}(\mathrm{mg} / \mathrm{g}) \\ \mathrm{SSE} & \text { Sum of square errors } \\ \chi^{2} & \text { Chi squared test } \\ R^{2} & \text { Correlation coefficient } \\ \text { FFED } & \text { Fractional factorial experimental design } \\ \Delta G^{\circ} & \text { Standard free energy }\end{array}$

\section{$\Delta \mathrm{S}^{\circ} \quad$ Entropy change \\ $\Delta \mathrm{H}^{\circ} \quad$ Enthalpy change}

\section{Introduction}

Textile industries are one amongst ten top polluting industries in the world [19]. These industries are the major consumers of dyes. Textile industries adopt wet processes which consume approximately 9 trillion gallons of water [73] and generate millions of liters of effluent containing thousands of tons of dyes [38]. The dyes are designed in such a way that they could not be faded away by any

Akheel Ahmed Syed, akheelahmed54@gmail.com | 'Department of Studies in Environmental Science, University of Mysore, Manasa Gangothri, Mysuru 570006, India. ${ }^{2}$ Department of Agriculture, Faculty of Agriculture and Veterinary Medicine, Thamar University, Dhamar, Republic of Yemen. ${ }^{3}$ Department of Chemistry, University of Malaya, Kuala Lumpur 50603, Malaysia. ${ }^{4}$ LAQV-REQUIMTE, Department of Chemistry, Faculty of Science and Technology, Universidade NOVA de Lisboa, 2829-516 Caparica, Portugal. ${ }^{5}$ Department of Studies in Chemistry, University of Mysore, Manasa Gangothri, Mysuru 570006, India.

SN Applied Sciences (2019) 1:330 | https://doi.org/10.1007/s42452-018-0125-5 
of the physical, chemical, and biological agents. Consequently, dye removal is a difficult process because of the diversity in dye structure and other constituents present in industrial effluent. Hence, they cannot be destroyed and/ or degraded by ordinary treatment processes. The color discharges from industries have unpleasant appearance and pose ecological and public health problems. These industries at present are having problems including severe competition, over-capacity, low profit margins, and strict environmental regulations. This has resulted in restrictions for overhead expenditures towards R\&D and wastewater treatment. Hence, economical removal of color and toxicity from effluents assumes paramount importance.

The rising demand for nutraceuticals across the world as alternative to allopathy or modern systems of medicine has attracted the attention of many industries including pharmaceutical companies. Transparency Market Research, a firm providing Current Market Trends has forecasted that the global nutraceuticals market is expanding at a compound annual growth rate of $7.3 \%$ during 2015 to 2021 and it was valued at US\$ 182.6 bn in 2015; will go up to US\$278.95 bn by the end of 2021 [18]. The Nutraceutical Industry is facing problems of handling waste generated during recovery of the nutraceuticals. The waste produced after mechanical, thermal and chemical processes are commonly known as nutraceutical industrial spent (NIS). Consequently, these spent have neither feed and/ or fertilizer value. Furthermore, most of the spent have fibril structure which traps moisture which decreases the calorific value. Hence, it cannot be used as a fuel. Though information is lacking about the quantity spent/waste generated in nutraceutical industrial sector, but, looking at the extent of market turn-over, the annual renewable spent/waste generated may run into millions of tons. Handling myriad tons of NIS is a daunting task and needs to be addressed on a sustainable approach.

Acid blue 113 (AB113) belongs to the category of bisazo dyes. The simple synthesis process of azo dyes in aqueous medium coupled with vast choice of starting materials have made possible to get wide spectrum of shades and fastness properties. These can be used on a variety of substrates. Most of the azo dyes are toxic and mutagenic. These dyes have been banned in all over the world. But because of their low price and other advantages, these dyes are still produced all over the world. The toxicity of azo dyes arises from their degradation products. The most labile part of the azo dye is its azo linkage. This part undergoes breakdown by azo reductase enzyme present in various microorganisms and mammals including humans. The enzyme accelerates the release of constituent aromatic amines several of which are highly toxic and carcinogenic [3].
The techniques, methods and procedures reported in literature for the remediation of $A B 113$ dye can be broadly classified into biological-cum-chemical [13, 20, 21, 28, 51] electrocoagulation [39], physical methods using UV radiations [36, 44, 46-48], photocatalytic degradation [66, 74], low frequency ultrasound assisted degradation [40], nanomaterials [49] and use of inorganic materials including activated carbons [16, 34, 42, 43, 45, 63]. Nevertheless, huge initial cost in installing operational plant, high-operational cost, regeneration problem, secondary pollutants, sensitivity to variations in wastewater input, interference by some wastewater constituents, and residual sludge generation are some associated problems in these methods $[11,61]$. Adsorption techniques of late have gained prominence due to their efficiency in the removal of pollutants that are not amenable to any other conventional methods.

The process of adsorption involves three advantages in removing toxic dyes from aqueous solutions and these include, (1) simple in operation, (2) treatment process is of high efficiency and treated water is free from harmful products, and (3) easy for scaling up from laboratory to field level [69]. Adsorbents such as activated carbon and nanofibers have been investigated for the removal of $A B 113$ from water. Ideal biosorbent for remediation of dyes should (1) be available in abundance and at low cost; (2) have no or minimal other use(s) so that price rise is controlled and there is limited demand; (3) be available in ready-to-use form without requiring any prechemical treatment; (4) possess such pore structure as to allow better adsorption and (5) be adoptable to simple and cost-effective technology to reuse the sludge/ toxic biomass produced after the remediation process. In this respect the use of nutraceutical industrial Tribulus terrestris spent (NITTS) for the bioremediation of AB113 from waste water meets the needs and demands of textile industries.

Tribulus terrestris is a nutraceutical and belongs to Zygophyllaceae family which comprises of about 20 species and amongst these Tribulus cistoides, T. terrestris, and Tribulus alatus, are common in India [67]. Among these, T. terrestris is a medicinal herb well patronized by nutraceutical industries [12]. It is an annual shrub found in India, China, southern USA, Mexico, Spain, and Bulgaria [30]. The fruit is spiky having five almost wedge-shaped, woody cocci, comprising of sharp spines. Spine tips meet in pairs and form framework around the fruit. Each coccus contains many seeds. Fruit odor is slightly aromatic with acrid taste. Extracts and steroidal saponins have been found to possess various pharmacological activities [9]. The fruit of T. terrestris is subjected to extraction of principle component(s) by mechanical, chemical and thermal processes. The discarded residue, nutraceutical 
industrial T. terrestris spent (NITTS) has porous structure. The porous property of the spent is exploited to develop as a potential biosorbent for the separation of $A B 113$ in aqueous media.

Our research school is the first to report the use of NIS as filler material in the fabrication of thermoplastic and thermoset composites $[33,54-60,65]$ and for the use as effective adsorbents for remediation of Congo red, methylene blue and ethidium bromide dyes [32, 53, 64]. Despite myriad research papers reported the use of low-cost agriculture waste as biosorbent for the remediation of toxic dyes; very limited information is available about the use of dye adsorbed biosorbent commonly known as "sludge". We have reported on the use of "sludge" as filler material for the fabrication of thermoplastics and thermosets $[64,65]$.

\section{Materials and methods}

\subsection{Materials}

The dye used in this experiment is Acid Blue 113 (AB113) also commonly referred to as Neutral Blue $5 \mathrm{R} ;[\mathrm{Cl} 26,360$; CAS Number: 3351-05-1; chemical formula $=\mathrm{C}_{32} \mathrm{H}_{21} \mathrm{~N}$ ${ }_{5} \mathrm{Na}_{2} \mathrm{O}_{6} \mathrm{~S}_{2}$; molecular weight $=681.65$; absorbance maxi$\left.\operatorname{mum}\left(\lambda_{\max }\right)=566 \mathrm{~nm}\right]$. The molecular structure of the dye is shown in Fig. 1.<smiles>Nc1c(N=Nc2cccc([N+](=O)[O-])c2)c(S(=O)(=O)O[Na])cc2cc([SH](=O)(O)O[Na])c(N=Nc3ccccc3)c(O)c12</smiles>

Fig. 1 Structure of Acid Blue 113

\subsection{Adsorbent preparation and characterization}

\subsubsection{Adsorbent preparation}

NITTS was procured from a local factory to get sample as close to real world application as possible. The NITTS was initially dried in sunlight, crushed and finally ground using a ball mill and sieved to get ASTM standard particle size: $(\leq 90, \geq 90 \leq 125, \geq 125 \leq 177, \geq 177 \leq 355, \geq 355 \leq 500, \geq 50$ $0 \leq 710 \mu$ ). T. terrestris and NITTS are shown in Fig. 2a, b.

\subsubsection{Surface characterization}

The surface morphology of NITTS was visualized through Electronic Microscope (LEO 435 VP model, Japan). The functional groups were assessed through FTIR. Infrared spectra (Inter-spec 2020, Spectro Lab, UK) of NITTS before and after adsorption of $A B 113$ were taken.

The surface charge of NITTS was determined by preparing stock solution of $0.1 \mathrm{M} \mathrm{KCl}$. Fifty millilitres each of $0.1 \mathrm{M}$ $\mathrm{KCl}$ were transferred to seven $250-\mathrm{mL}$ Erlenmeyer flasks and $\mathrm{pH}$ was adjusted initially to 2.0 and 12.0 by using $\mathrm{HCl}$ and $\mathrm{NaOH}$. NITTS $(0.05 \mathrm{~g})$ was added to each flask. After allowing for $24 \mathrm{~h}$ the final $\mathrm{pH}$ was measured by $\mathrm{pH}$ meter (Systronics-802, India). Graph of $\mathrm{pH}_{\text {final }}$ versus $\mathrm{pH}_{\text {initial }}$ was plotted [8].

\subsubsection{Batch adsorption experiments}

The experiments were conducted in batches with varying parameters. However, the common preliminary preparation involved the setting up of $250-\mathrm{mL}$ flasks with $50 \mathrm{~mL}$ working aqueous solution of $A B 113(200 \mathrm{mg} / \mathrm{L})$. After the initial preparation, $50 \mathrm{mg}$ of NITTS were introduced into each flask. A temperature-controlled shaker was used to agitate the contents of the flasks at $165 \mathrm{rpm}$ for $3 \mathrm{~h}$. Results were collected by varying different parameters including dosage of NITTS $(0.025,0.050,0.075,0.100,0.150,0.200$, $0.300 \mathrm{~g} / 50 \mathrm{~mL}) ; A B 113$ concentration $(25,50,75,100,125$,
Fig. 2 a Tribulus terrestris, b nutraceutical industrial Tribulus terrestris spent

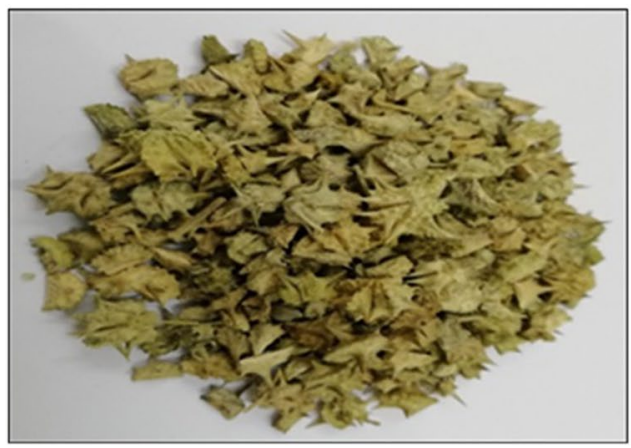

(a)

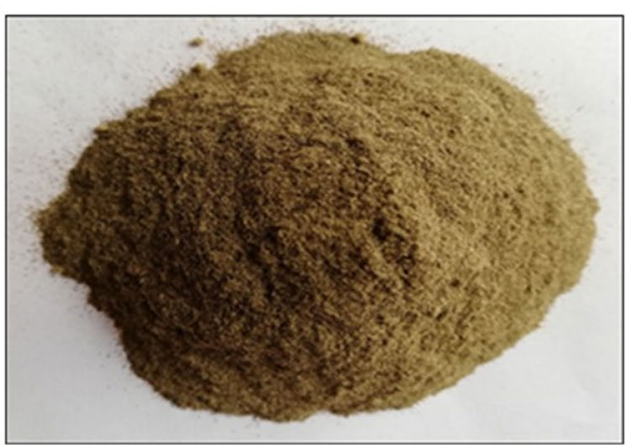

(b) 
$150,175,200,300,400$ and $500 \mathrm{mg} / \mathrm{L})$; adsorbent particle size $(\leq 90, \geq 90 \leq 125, \geq 125 \leq 177, \geq 177 \leq 355, \geq 355 \leq 500$, $\geq 500 \leq 710 \mu), \mathrm{pH}(2,4,6,7,8,10$ and 12$)$ and temperature ( $303 \mathrm{~K}, 313 \mathrm{~K}$ and $323 \mathrm{~K}$ ) with dye concentrations of 100 , 200, $300 \mathrm{mg} / \mathrm{L}$. The samples were centrifuged at $3000 \mathrm{rpm}$ for $5 \mathrm{~min}$ to remove the leftover particulate matter. In case, the solution is not clear, the centrifugation was continued for additional five minutes. UV-Vis Spectrophotometer (Perkin Elmer-Lambda 25, USA) was used to measure the absorbance of the filtrate at $566 \mathrm{~nm}$. Controls were maintained by using the adsorbent in distilled water and an adsorbent-free $A B 113$. The amount of AB113 adsorbed at equilibrium, $q_{e}(\mathrm{mg} / \mathrm{g}$ ) was calculated by using Eq. (1).

$q_{e}=\left(C_{0}-C_{e}\right) \frac{V}{W}$

where, $C_{0}$ and $C_{e}$ are initial and equilibrium concentrations (mg/L) of $A B 113, V$ is solution volume $(\mathrm{L})$ and $W$ is adsorbent weight $(\mathrm{g})$.

Kinetic studies were also done by adopting same procedure, however the aqueous samples at pre-set time intervals. For measuring AB113 dye concentration several methods were used. The quantum of $A B 113$ adsorbed at any specific time, $q_{t}(\mathrm{mg} / \mathrm{g})$, was calculated as follows (2).

$q_{t}=\left(C_{0}-C_{t}\right) \frac{V}{W}$

$C_{t}(\mathrm{mg} / \mathrm{L})$ implies the $\mathrm{AB} 113$ concentration at time $\mathrm{t}$. Initial dye concentrations used were 50, 100 and $200 \mathrm{mg} / \mathrm{L}$ and absorption time given was $60 \mathrm{~min}$ ( $5 \mathrm{~min}$ intervals) were studied. To know the optimum adsorbent amount per unit adsorbate mass $50 \mathrm{~mL}$ of dye were contacted with varying quantity of NITTS $0.025-0.300 \mathrm{~g} / 50 \mathrm{~mL}$ $(0.500-6.000 \mathrm{~g} / \mathrm{L})$ until there was equilibrium. $\mathrm{pH}$ influence on dye adsorption was noted by agitating $50 \mathrm{mg}$ of NITTS along with $50 \mathrm{~mL}$ of dye concentration $(200 \mathrm{mg} / \mathrm{L}$ ) using orbital shaker. The experiment was repeated with $\mathrm{pH}$ values ranging from 2 to 12 . Agitation was done for 180 min; but equilibrium was reached in 140-150 min with agitation speed of $165 \mathrm{rpm}$. Based on this all further agitations were done at $165 \mathrm{rpm}$ for $180 \mathrm{~min}$. Dye concentration was measured at equilibrium by using double beam UV/ Vis spectrophotometer at $\lambda_{\max } 590 \mathrm{~nm}$. Dilute $\mathrm{HCl}$ and or $\mathrm{NaOH}$ were used for $\mathrm{pH}$ adjustment. $\mathrm{pH}$ meter was used for $\mathrm{pH}$ determination (Systronics 802, India). Dye removal was assessed using following Eq. (3).

Dyeremoval efficiency $\%=\frac{\left(C_{0}-C_{e}\right)}{C_{o}} \times 100$

Different parameters involved in eight adsorption isotherms selected for study, their units and significance are presented in Table 1. Absorption experiments were done in triplicate and the results are the means of three replicates.

\subsubsection{Statistical optimization of process parameters}

Factors influencing the adsorption process and final adsorption capacity like duration of contact time (A), temperature (B), dye concentration (C), particle size (D), adsorbent dosage $(\mathrm{E})$ and $\mathrm{pH}(\mathrm{F})$ were studied. These independent variables were optimized for adsorption capacity which is the dependent response variable at fixed orbital shaking at $165 \mathrm{rpm}$. A standard experimental design was prepared comprising six factors at two levels (Table 2). Analysis of variance yielded a general quadratic regression equation. Finally surface and contour plots were prepared by which the individual and interaction effects of parameters responsible for adsorption could be graphically depicted.

\subsection{Determination of AB113 dye in textile industrial effluent}

Different processes employed in textile industry generate waste water with varied compositions containing large amounts of suspended solids, highly fluctuating $\mathrm{pH}$, variable temperature, intense color and COD concentration [23]. Therefore, it is difficult to identify a specific dye in industrial effluent due to matrix effect [62]. A simple procedure was developed to compare the remediation of $A B 113$ dye in water as also in textile industrial effluent.

\subsubsection{Textile industrial effluent (TIE)}

Effluent samples were collected from a local textile industry which operates in two shifts. Six random TIE samples were collected in 10-L polyethylene containers from the end of the pipe where the effluent enters into the treatment plant. Among the six samples, three were collected from first and second shifts consecutively on three working days. All textile industrial effluent samples collected were transferred to a 100-L barrel and stirred manually to get uniform concentration. The resulting solution was used as control TIE sample for analyses. Sampling, preparation and preservation methods while collecting the effluent samples from the industries were in accordance with standard methods [2,52].

\subsubsection{Preparation of AB113 in distilled water}

After transferring $2 \mathrm{~g}$ of AB113 to a 2-L standard flask, it was dissolved using distilled water and it was made up to the mark. The solution was thoroughly stirred to get uniform concentration (Solution 1). 
Table 1 Different parameters involved in adsorption isotherms, units and significance

\begin{tabular}{|c|c|c|c|c|}
\hline Isotherm & Expression & Parameters & Units & Significance of the parameters \\
\hline Langmuir & $q_{e}=\frac{Q_{m} K_{a} C_{e}}{1+K_{a} C_{e}} R_{L}=\frac{1}{1+K_{a} C_{0}}$ & $Q_{m}, K_{a}$ & $\begin{array}{l}C_{o} \text {-adsorbate initial concentration } \\
\text { (mg/L) } \\
C_{e}-\text { equilibrium concentration } \\
\text { (mg/L) } \\
Q_{m}-\text { maximum adsorption capacity } \\
\text { (mg/g) }\end{array}$ & $\begin{array}{l}R_{L} \text { imply whether the adsorption } \\
\text { is unfavourable }\left(R_{L}>1\right) \text {, Linear } \\
\left(R_{L}=1\right) \text {, favourable }\left(0<R_{L}<1\right) \text { or } \\
\text { irreversible }\left(R_{L}=0\right)\end{array}$ \\
\hline Freundlich & $q_{e}=K_{F} C_{e}^{1 / n_{F}}$ & $K_{F}, n_{F}$ & $\begin{array}{l}n_{F} \text {-Freundlich isotherm constant } \\
(\mathrm{mg} / \mathrm{L})^{-1 / n} \text { related to adsorption } \\
\text { capacity }\end{array}$ & $\begin{array}{l}n_{F} \text { is heterogeneity factor which } \\
\text { indicates whether the nature of } \\
\text { adsorption is linear }\left(n_{F}=1\right) \text {, chem- } \\
\text { isorption }\left(n_{F}<1\right) \text {, or physisorption } \\
\left(n_{F}>1\right)\end{array}$ \\
\hline Toth & $q_{e}=q_{m} C_{e}\left(b_{\mathrm{T}}+C_{e \mathrm{~T}}^{n}\right)_{\mathrm{T}}^{-1 / n}$ & $q_{m}, b_{T}, n_{T}$ & $b_{T}$-Tempkin isotherm constant & \\
\hline Sips & $q_{\mathrm{e}}=q_{m}\left(K_{\mathrm{s}} C_{\mathrm{e}}\right) m_{\mathrm{s}} /\left(K_{\mathrm{S}} C_{\mathrm{e}}\right) m_{\mathrm{S}}$ & $q_{m^{\prime}} K_{\mathrm{s}}, m_{\mathrm{S}}$ & $\begin{array}{l}q_{e \_ \text {adsorption capacity }(\mathrm{mg} / \mathrm{g})} \\
K_{\mathrm{S}} \text {-Sips isotherm model constant } \\
(\mathrm{L} / \mathrm{g})\end{array}$ & \\
\hline Radke-Prausnitz & $q_{e}=K_{\mathrm{RP}} q_{m} C_{\mathrm{e}} /\left(1+K_{\mathrm{RP}} C_{\mathrm{e}}\right) m_{\mathrm{RP}}$ & $K_{\mathrm{RP}}, m_{\mathrm{RP}}$ & $\begin{array}{l}K_{R P}, m_{R P}-\text { Radke-Prausnitz iso- } \\
\text { therm model exponent }\end{array}$ & \\
\hline Redlich-Peterson & $q_{e}=\frac{A_{R P} C_{e}}{1+B_{R P} C_{e}^{g}}$ & $A_{R P}, B_{R P}, g$ & $\begin{array}{l}A_{R P}, B_{R P}-\text { Redlich-Peterson iso- } \\
\text { therm model exponent }\end{array}$ & $\begin{array}{l}\text { Langmuir isotherm }(g=1) \text { or Freun- } \\
\text { dlich isotherm }(g=0)\end{array}$ \\
\hline Vieth-Sladek & $q_{e}=K_{V S} C_{e}+\frac{Q m \beta_{V S} C_{e}}{1+\beta_{V S} C_{e}}$ & $K_{V S}, \beta_{V S}$ & $\begin{array}{l}K_{V S}, \beta_{V S}-V i e t h-S l a d e k \text { isotherm } \\
\text { model exponent }\end{array}$ & \\
\hline Brouers-Sotolongo & $q_{e}=Q_{m}\left[\left(1-\exp \left(-K_{B S}\left(C_{e}\right)^{\alpha}\right)\right]\right.$ & $K_{B S}, a$ & $K_{B S}, a$-Brouers-Sotolongo constants & \\
\hline
\end{tabular}

Table 2 Factors considered for experimental design along with their high and low levels

\begin{tabular}{lllll}
\hline Factor & Parameter & Units & Minimum & Maximum \\
\hline A & Duration of contact time & Minutes & 0 & 180 \\
$\mathrm{~B}$ & Temperature & ${ }^{\circ} \mathrm{C}$ & 27 & 50 \\
$\mathrm{C}$ & Concentration & $\mathrm{mg} / \mathrm{L}$ & 25 & 500 \\
$\mathrm{D}$ & Particle size & $\mu$ & 90 & 710 \\
$\mathrm{E}$ & Adsorbent dosage & $\mathrm{g} / \mathrm{L}$ & 0.50 & 6.00 \\
$\mathrm{~F}$ & $\mathrm{pH}$ & & 2 & 12 \\
\hline
\end{tabular}

\subsubsection{Preparation of $A B 113$ in textile industrial effluent}

$A B 113(2 \mathrm{~g})$ was transferred to a $2-\mathrm{L}$ standard flask and was dissolved in TIE. By adding TIE the solution was made up to the mark. Stirring was done to get uniform concentration of the solution (Solution 2).

\subsubsection{Blank experiment}

Five hundred $\mathrm{ml}$ of distilled water were transferred to a 1-L conical flask containing 5-cm Teflon coated magnetic bar.
Five grams of NITTS were added and the solution stirred at about $700 \mathrm{rpm}$ for $15 \mathrm{~min}$ using a magnetic stirrer. The solution was filtered using No 42 Whatman filter paper and the filtrate solution was compared with the solution obtained after remediation of dye loaded-TIE.

\subsection{Procedures}

\subsubsection{Measurement of the absorbance of stock solutions}

An aliquot of TIE solution was filtered through Buchner funnel using No 42 Whatman filter paper and by using UV-Vis Spectrophotometer (Perkin Elmer-Lambda 25, USA) absorbance of the filtrate was measured using maximum absorbance scale of 3.0. This absorbance range was used for all further measurements. However, in case of concentrated solutions, the absorbance was measured after appropriate dilution and the resultant absorbance was multiplied by the dilution factor to get the absorbance of concentrated solution. This procedure was adopted to measure the absorbance of Solution 1 and Solution 2. 


\subsubsection{Measurement of molar absorption coefficient $(\varepsilon)$ of $A B 113$}

Six different concentrations $\left(1.00 \times 10^{-4} ; 1.25 \times 10^{-4}\right.$; $2.50 \times 10^{-4} ; 5.00 \times 10^{-4} ; 7.50 \times 10^{-4}$ and $10.00 \times 10^{-4}$ ) of $A B 113$ were prepared in distilled water and the absorbance was measured at $566 \mathrm{~nm}$ using distilled water as reference Fig. 11a. A graph of absorbance versus concentration was plotted. $\varepsilon$ was measured from the slope of the linear portion of the curve or by using mathematical formula $\varepsilon=A / c l$ where $A$ is specific absorption coefficient for concentration c (mol/L) for a path length of $1 \mathrm{~cm}$. Specific absorption coefficient or absorbency index is the absorbance per unit path length and unit concentration. In case of the latter the $\varepsilon_{\mathrm{AB} 113}$ was calculated as the mean of six values as follows:

$\varepsilon_{\mathrm{AB} 113}=\varepsilon 1+\varepsilon 2+\varepsilon 3+\varepsilon 4+\varepsilon 5+\varepsilon 6 / 6$

$\varepsilon_{\mathrm{AB} 113}=2450+2440+2424+2402+2396+2411 / 6=2421$

\subsubsection{Procedure for the remediation of $A B 113$ at macro scale}

Step 1 Five hundred millilitres of Solution 1 were transferred to 1-L conical flask. Five grams of NITTS were added to the conical flask and the solution was agitated using magnetic stirrer at about $700 \mathrm{rpm}$. At the end of 15 min the agitation was stopped and solution was filtered through No 42 Whatman filter paper using Buchner funnel apparatus. If the filtrate is not clear the filtration was repeated and absorbance recorded.

Step 2 The dye-adsorbed NITTS on the filter paper of the Step 1 was carefully transferred from a Buchner funnel to a watch glass and kept in an oven at $60^{\circ} \mathrm{C}$ for $24 \mathrm{~h}$ for drying. The dried powder was scrapped using spatula and transferred to a watch-glass.

Step 3 Second portion of $5 \mathrm{~g}$ NITTS was added to the conical flask containing filtrate solution from Step 1 and agitation was continued on a magnetic stirrer at about $700 \mathrm{rpm}$ for $15 \mathrm{~min}$. At the end of $15 \mathrm{~min}$ the agitation was stopped and solution was filtered through No 42 Whatman filter paper using Buchner funnel apparatus. If the filtrate is not clear the filtration was repeated and absorbance recorded.

Step 4 The dye-adsorbed NITTS on the filter paper of the Step 3 was carefully transferred from a Buchner funnel to a watch glass and kept in an oven at $60^{\circ} \mathrm{C}$ for $24 \mathrm{~h}$ for drying. The dried powder was scraped using spatula and transferred to a watch-glass.

Step 5 Third portion of $5 \mathrm{~g}$ NITTS was added to the conical flask containing filtrate solution from Step 3 and agitation was continued on a magnetic stirrer at about $700 \mathrm{rpm}$ for $15 \mathrm{~min}$. At the end of $15 \mathrm{~min}$ the agitation was stopped and solution was filtered through No 42 Whatman filter paper using Buchner funnel apparatus. If the filtrate is not clear the filtration was repeated and absorbance recorded.

Step 6 The dye-adsorbed NITTS on the filter paper of the Step 5 was carefully transferred from a Buchner funnel to a watch glass and kept in an oven at $60^{\circ} \mathrm{C}$ for $24 \mathrm{~h}$ for drying. The dried powder was scrapped using spatula and transferred to a watch-glass.

Step 7 Fourth portion of $5 \mathrm{~g}$ NITTS was added to the conical flask containing filtrate solution from Step 5 and agitation was continued on a magnetic stirrer at about $700 \mathrm{rpm}$ for $15 \mathrm{~min}$. At the end of $15 \mathrm{~min}$ the agitation was stopped and solution was filtered through No 42 Whatman filter paper using Buchner funnel apparatus. If the filtrate is not clear the filtration was repeated and absorbance recorded.

Step 8 The dye-adsorbed NITTS on the filter paper of the Step 7 was carefully transferred from a Buchner funnel to a watch glass and kept in an oven at $60^{\circ} \mathrm{C}$ for $24 \mathrm{~h}$ for drying. The dried powder was scraped using spatula and transferred to a watch-glass.

Step 9 Steps 1 to 8 were repeated with Solution 2 .

\section{Results and discussion}

\subsection{Characterization of the adsorbent}

\subsubsection{Surface characterization}

Surface characterization of NITTS was done through SEM which exhibited slightly porous structure (Fig. 3a). After the adsorption of AB113 Fig. 3b some pores got completely filled with the adsorbate forming a thin film over the particle. IR spectra of NITTS provided that the broadband between 3353 and $3454 \mathrm{~cm}^{-1}$ in the IR spectrum of NITTS is attributed to the hydroxyl groups of cellulose and adsorbed water molecule (Fig. 4). A weak sharp band at $2852 \mathrm{~cm}^{-1}$ is due to the $\mathrm{C}-\mathrm{H}$ stretching and band at $1598 \mathrm{~cm}^{-1}$ is due to $\mathrm{C}-\mathrm{O}$ stretching. Further, the bands at $1418,1404,1355,1158$ and $1091 \mathrm{~cm}^{-1}$ are attributed to the $\mathrm{C}-\mathrm{O}-\mathrm{C}$ stretching. After adsorption of AB113 onto NITTS, it was observed in the IR spectrum that the broad bands between 3300 and $3500 \mathrm{~cm}^{-1}$ due to $\mathrm{N}-\mathrm{H}$ stretching of $-\mathrm{NH}_{2}$ group in $\mathrm{AB} 113$ and between 3353 and $3454 \mathrm{~cm}^{-1}$ due to the hydroxyl groups of NITTS disappeared which confirmed the formation of hydrogen bonds between $-\mathrm{NH}_{2}$ and hydroxyl groups. In addition, the disappearance of a strong peak at $1598 \mathrm{~cm}^{-1}$ for N-N Stretching confirmed the strong adsorption of AB113 onto NITTS. Finally, based on the disappearance of IR absorption frequencies, it could be attributed that to a large extent AB113 
Fig. 3 a SEM image of NITTS, $\mathbf{b}$ SEM image of $A B 113$ adsorbed on NITTS

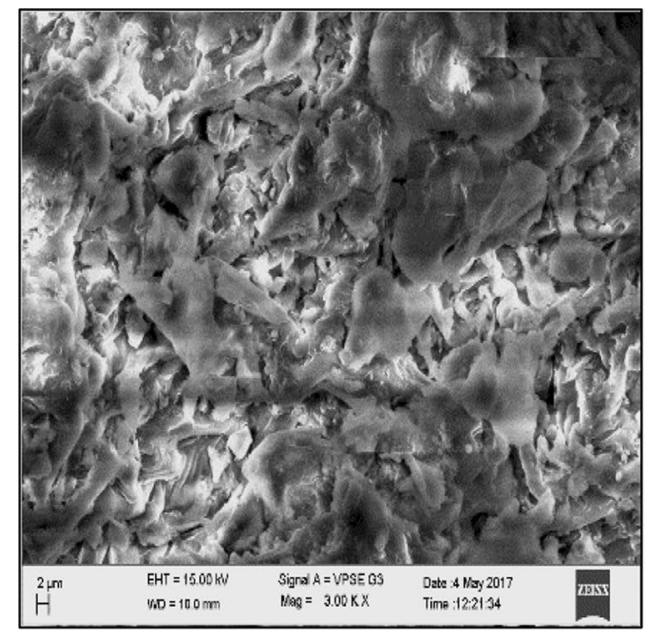

(a)

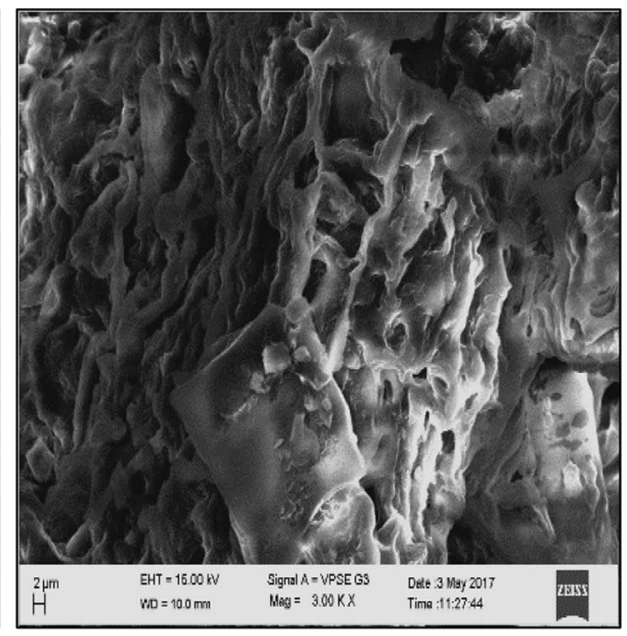

(b)

Fig. 4 FTIR spectra of AB113, NITTS and $A B 113$ adsorbed on NITTS

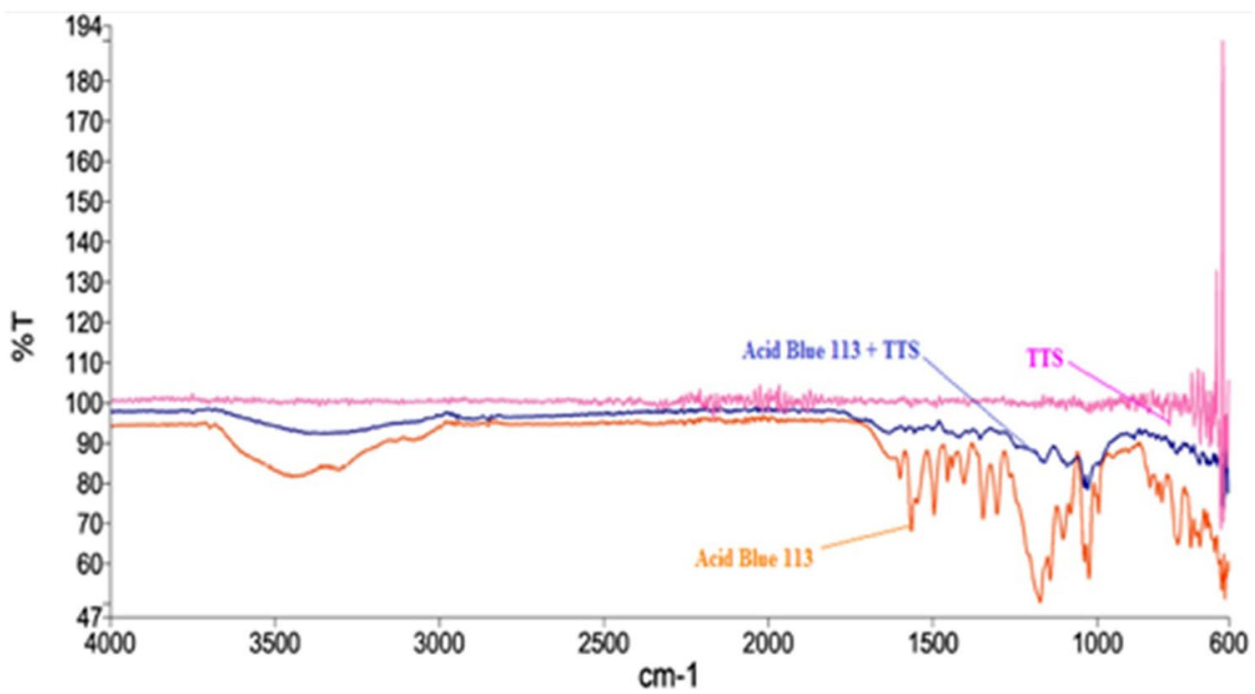

has adsorbed onto NITTS. Determination of point of zero charge at intersection of two plots (Fig. 5), confirmed that at $\mathrm{pH} 7.5$ the adsorbent surface has zero charge.

\subsection{Batch adsorption studies}

\subsubsection{Effect of $\mathrm{pH}$ and dye concentration}

It is the ultimate need to determine the optimal status of each parameter to get maximum adsorption. $\mathrm{pH}$ is the prime parameter in adsorption process since it has the capacity to control adsorption process. This is achieved by its influence on adsorbent surface properties and also ionic forms of dye in the solution. At pH 2, maximum adsorption capacity was observed Fig. 6a and when $\mathrm{pH}$ increased from 2 to 4 , adsorption decreased drastically and remained almost constant till pH 12 . The maximum AB113 removal by NITTS was at $\mathrm{pH} 2.0$

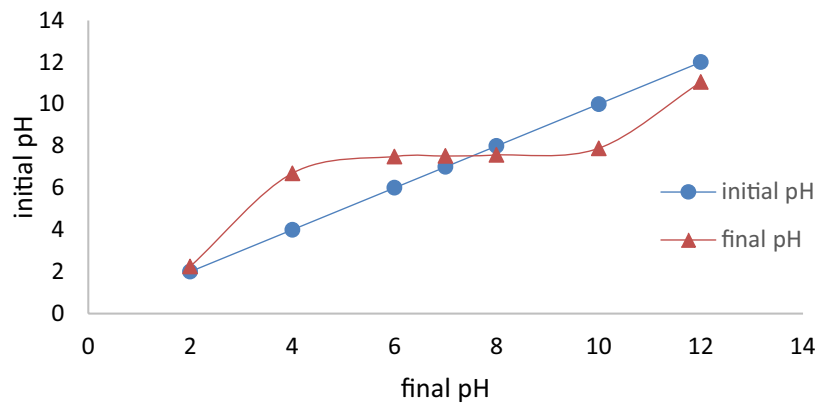

Fig. 5 Point of zero charge of NITTS at the intersection

$\left(q_{e}=93.00 \mathrm{mg} / \mathrm{g}\right)$ with initial concentration of $100 \mathrm{mg} / \mathrm{L}$. The $q_{e}$ value increases with increase in initial dye concentration as shown in Fig. $6 \mathrm{~b}$. The $\% q_{e}$ value increased with increase in concentration and reached maximum 
(a)

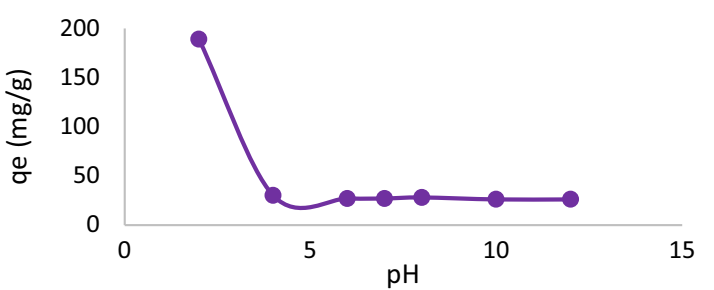

(b)

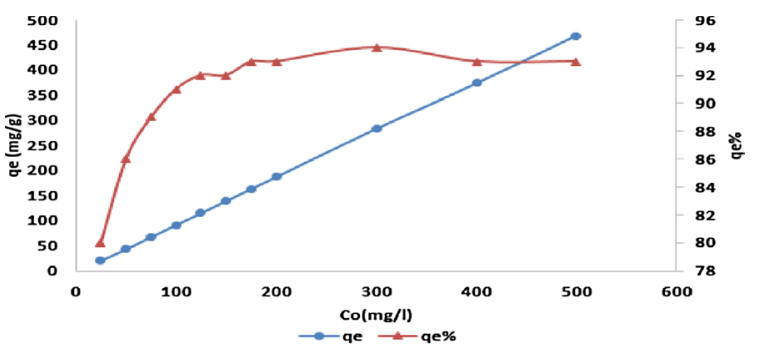

(c)

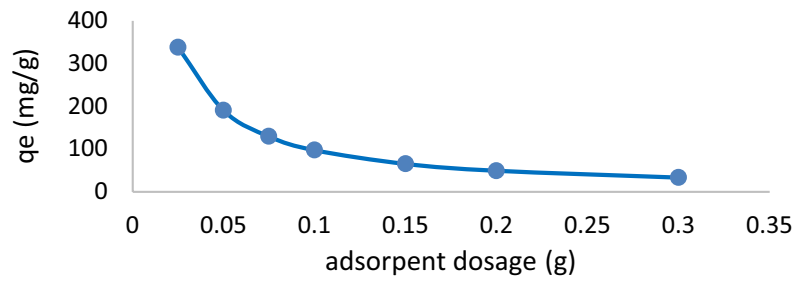

(d)

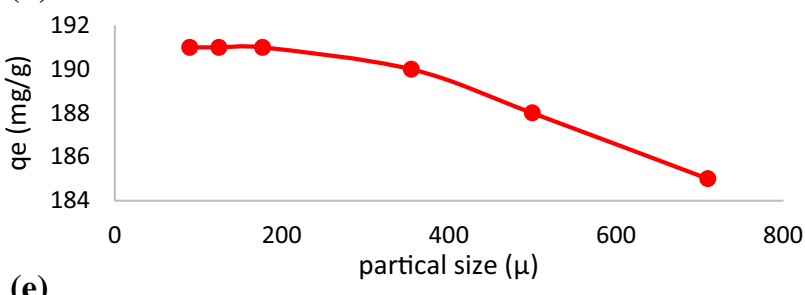

(e)

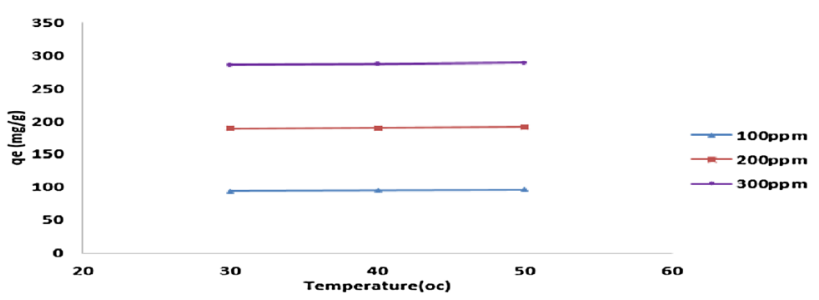

Fig. 6 a Effect of pH on adsorption of dye, $\mathbf{b}$ effect of initial dye concentration, $\mathbf{c}$ effect of adsorbent dosage on adsorption of dye, $\mathbf{d}$ Effect of adsorbent particle size on dye adsorption, e effect of temperature on adsorption of dye

in the range of $100-200 \mathrm{mg} / \mathrm{L}$ solution concentration. Thereafter, $\% q_{e}$ value remained almost constant.

\subsubsection{Effect of adsorbent dosage}

The adsorption process is highly influenced by the adsorbent dose. The adsorbent dosage in the range of 0.025 to $0.300 \mathrm{~g}$ in $50 \mathrm{~mL}$ dye solution on adsorption was investigated. The result showed that AB113 dye removal was more with higher adsorbent dosage. But beyond the limit there was no effect in enhancing the adsorbent dose on the yield of adsorbate. This happens because all the dye molecules get bound on to the adsorbent surface causing an equilibrium condition between the molecules of dye on the adsorbent and in the solution [10]. The results are depicted in Fig. 6c.

\subsubsection{Effect of adsorbent particle size on dye adsorption}

Maximum adsorption capacity was determined for initial AB113 concentration of $100 \mathrm{mg} / \mathrm{L}$ at neutral $\mathrm{pH}$. Different particle sizes of $\leq 90 \mu \mathrm{m} ; \geq 90 \mu \mathrm{m} \leq 125 \mu \mathrm{m} ; \geq 12$ $5 \mu \mathrm{m} \leq 177 \mu \mathrm{m} ; \geq 177 \mu \mathrm{m} \leq 355 \mu \mathrm{m} ; \geq 355 \mu \mathrm{m} \leq 500 \mu \mathrm{m}$ and $\geq 500 \mu \mathrm{m} \leq 710 \mu \mathrm{m}$ were used in the experiment. The adsorption of dye decreased with the increase in the size of the adsorbent particle Fig. $6 \mathrm{~d}$. The observation is in conformity with the universal fact that surface area decreases by increasing particle size. The size of $\geq 125 \mu \mathrm{m} \leq 177 \mu \mathrm{m}$ (80 mesh ASTM) was selected for further studies because 80 mesh particle is widely employed in fabrication of composites and sieving to lower size particles takes longer period and adds to the cost of the process.

\subsubsection{Effect of temperature}

To understand the influence of temperature on adsorption, studies were done at $30-50{ }^{\circ} \mathrm{C}$ with three dye concentrations. The results in Fig. 6e show that with increase in temperature, the adsorption rate decreases indicating that it is an endothermic process. The influence of temperature on adsorption could be because of the movement of dye molecules and lowering of kinetic energy ultimately causing an increased rate of intra-particle diffusion process [10].

\subsubsection{Adsorption isotherm}

The process of adsorption describes a dynamic separation of solute from a solution onto an adsorbent. Equilibrium is established when the solute (AB113 dye) being adsorbed onto the adsorbent (NITTS) equal to the amount being desorbed. Thus, the adsorption equilibrium may be defined as the ratio between the adsorbed amount and that which is remaining in the solution. This can be established when the adsorbate phase contacts the adsorbent for sufficient time, under given experimental conditions. This results in establishing a dynamic balance with the interface concentration [15, 24]. Under the equilibrium condition the solution concentration remains almost constant. By plotting solid phase concentration against liquid phase concentration it is possible to depict the equilibrium adsorption isotherm. 
Equilibrium adsorption isotherm plays an important role in developing mathematical equation which represents the concentration data obtained from the experiments at equilibrium and predicts the possible maximum adsorption capacity $\left(Q_{m}\right)$. In brief, an adsorption isotherm is the successful representation of the dynamic adsorptive separation of solute from solution onto an adsorbent and this depends on appropriate description of the equilibrium separation between the two phases. Both the adsorption mechanism and the surface properties and affinity of the adsorbent can be understood from the equation parameters and the underlying thermodynamic assumptions of these isotherm models. In the modeling analysis, operation design and application of the adsorption process plays an important role. This is graphically depicted by illustrating the solid-phase against its residual concentration [31]. The physicochemical parameters along with the thermodynamic assumptions show the insight of mechanism involved in adsorption, properties of the surface as well as the adsorbents extent degree of affinity [7].

Over the years, a wide variety of equilibrium isotherm models have been formulated in terms of three fundamental approaches [29]. First approach is kinetic consideration, which defines the equilibrium as a state of dynamic equilibrium, with both adsorption and desorption rates being equal. In the second approach it is possible to get a base for thermodynamics - an outlay which derives different forms of adsorption isotherm models. The third approach provides major idea involved in the generation of typical curve. In the isotherm modeling the interest lies in the derivation by more than one approach, which directs to the variation in the interpretation of the model parameters. Its physicochemical parameters together with the underlying thermodynamic assumptions provide an insight into the adsorption mechanism, surface properties as well as the degree of affinity of the adsorbents [7].

Various isotherm equations have been used to describe the equilibrium characteristics of adsorption. In the present study, the best fit of two-parameter isotherm models namely, Langmuir [26] and Freundlich [14]. The separation factor $R_{L}$ is important for Langmuir isotherm [72]. Six threeparameter isotherm models namely, Redlich-Peterson [37], Toth [68], Sips [50], Radke-Prausnitz [35], Vieth-Sladek [70] and Brouers-Sotolongo [6] isotherm models were compared using the experimental equilibrium data of $A B 113$ onto NITTS are shown in Fig. 7a-d. The calculated and statistical parameters of two-parameter and three-parameter isotherm models are presented in Table 3. From the Table 3, it can be observed that higher $R^{2}$ values of 0.97 and 0.98 for all the isotherm models suggest the applicability of these models to represent the equilibrium adsorption of $A B 113$ by NITTS. However, the validity of data fitting cannot be confirmed by $R^{2}$ value alone as it is used only with linear
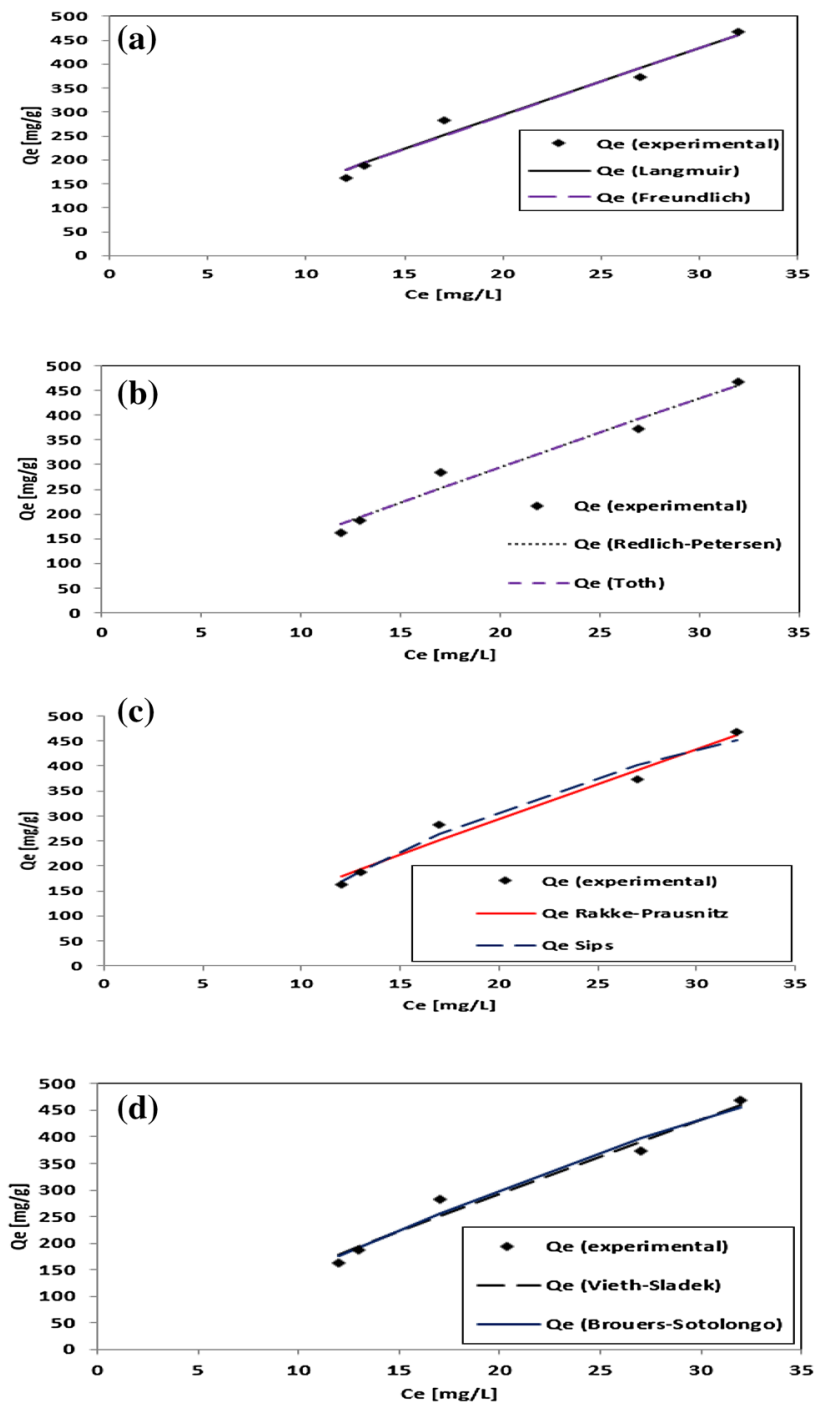

Fig. 7 a Fitting of adsorption data to Langmuir and Freundlich adsorption isotherms, b fitting of adsorption data to RedlichPetersen and Toth adsorption isotherm, c fitting of adsorption data to Radke-Prausnitz and Sips adsorption isotherm, $\mathbf{d}$ fitting of adsorption data to Vieth-Sladek and Brouers-Sotolongo adsorption isotherms

models. For the last three decades, linear regression has been considered as one of the most viable tool defining the best-fitting relationship [22] quantifying the distribution of adsorbate, mathematically analyzing the adsorption system [27] and verifying the consistency and theoretical assumptions of an isotherm model [5]. Due to the inherent bias several rigorous error functions have been reported. Presently, we have chosen two functions namely, sum square error (SSE) and Chi square $\left(\chi^{2}\right)$ test. The higher magnitude of the values of SSE and lower values of $\chi^{2}$ indicate similarities. A closer look at the error functions and $Q_{m}$ values suggest Sips and Brourers-Sotolongo models are better fits compared to other models. However, disparity in the 


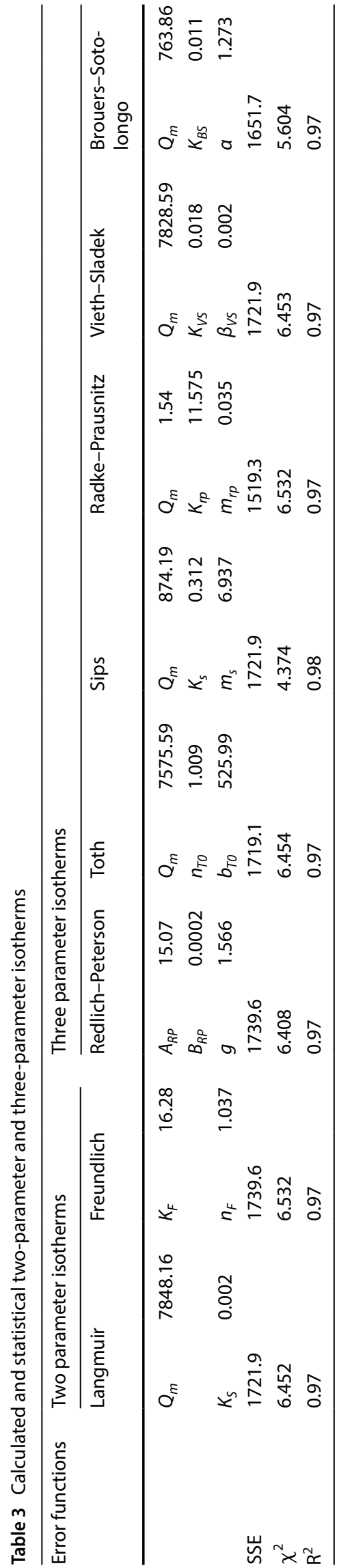

values obtained for $Q_{m}$ and $q_{e}$ will generate some interest and curiosity among scientist and it is more so with mathematical modeling community as they can think of developing newer models to improve this idea about adsorption phenomenon especially operating in AB113-NITTS system.

\subsubsection{Adsorption kinetics}

Kinetic models are used to study the rate of adsorption process. Three concentrations, viz., 100, 150 and $200 \mathrm{mg} / \mathrm{L}$ of $A B 113$ dye and three different temperatures $303 \mathrm{~K}$, $313 \mathrm{~K}$ and $323 \mathrm{~K}$ were selected to study the effect of these parameters on adsorption of dye onto NITTS. Data collected were analyzed by non-linear analyses (MS Excel 2010). Various models tried included pseudo-first order [25], pseudo-second order [17], intra-particle diffusion by Weber-Morris model [1], Dumwald-Wagner model [71] and Film Diffusion models [4]. Various parameters tested are presented in Table 4.

The results as reflected by coefficients of determination $\left(R^{2}\right)$ and Chi square values $\left(\chi^{2}\right)$ have proved that pseudo-second order model has fitted as compared to pseudo-first order with respect to all dye concentrations and all temperatures investigated Fig. 8a-c. The high adsorption rate was slowed down and became stagnant when maximum was reached. However, adsorption capacity $\left(q_{e}\right)$ was higher when temperature was increased. The process of adsorption is happening in multiple steps and it is not rate limiting. The molecules of solute (AB113 dye) in a solution moved towards the solid surface followed by diffusion into the pores of NITTS.

Dumwald-Wagner model Fig. 8d provides the exact absorption rate constant $(K)$ and also correction for diffusion effect (Table 5). As for Weber-Morris model Fig. 8e is concerned with solute uptake changes with $t^{1 / 2}$ but not with contact time $(t)$. In $q_{t}$ versus $t^{1 / 2}$ plot the straight line passes through the origin and in it the diffusion rate constant is indicated by the slope $\left(k_{\text {int }}\right)$. Adsorption kinetic has multiple control mechanisms as verified by present data in which all solute concentrations can be seen with more than one level of linearity. At lower concentration $(100 \mathrm{ppm})$ and temperature $(303 \mathrm{~K})$ absorption rate becomes higher followed by the rate being shifted as a result of varying linear trajectory and finally the rate becomes stabilized after some time. Adsorption becomes linear at higher temperatures, but the rate of adsorption is not affected at higher ( $200 \mathrm{ppm}$ ) solute concentration. Similar situation is witnessed when film diffusion model [4] is fitted with higher temperature data. From Fig. $8 \mathrm{f}$ and Table 5 it is evident that when temperature is higher there is maximum obstruction on adsorption rate by diffusional limitations. Hence it can be concluded that diffusion is a rate limiting process. Initially the solute adsorption on to the surface of particles is fast so that a film is formed 
Table 4 Experimentally determined and theoretically predicted parameters for absorption kinetics models

\begin{tabular}{|c|c|c|c|c|c|c|c|c|c|c|}
\hline \multirow{2}{*}{$\begin{array}{l}\text { Initial con- } \\
\text { centration } \\
(\mathrm{ppm})\end{array}$} & \multirow{2}{*}{$\begin{array}{l}\text { Temp } \\
(\mathrm{K})\end{array}$} & \multirow[b]{2}{*}{$Q_{e \text { expt }}(\mathrm{mg} / \mathrm{g})$} & \multicolumn{4}{|c|}{ Pseudo-first order } & \multicolumn{4}{|c|}{ Pseudo-second order } \\
\hline & & & $Q_{e \text { pred }}(\mathrm{mg} / \mathrm{g})$ & $k_{1}$ & $R^{2}$ & $\chi^{2}$ & $Q_{e \text { pred }}(\mathrm{mg} / \mathrm{g})$ & $k_{2}$ & $R^{2}$ & $\chi^{2}$ \\
\hline \multirow[t]{3}{*}{100} & 303 & 94 & 50.69 & $1.49 \mathrm{E}-01$ & 0.32 & 13.04 & 57.90 & $3.31 \mathrm{E}-03$ & 0.51 & 9.11 \\
\hline & 313 & 95 & 79.40 & $5.91 \mathrm{E}-02$ & 0.82 & 14.25 & 84.05 & $1.20 \mathrm{E}-03$ & 0.81 & 9.18 \\
\hline & 323 & 94 & 78.06 & $7.64 \mathrm{E}-02$ & 0.81 & 11.61 & 94.90 & $9.31 \mathrm{E}-04$ & 0.88 & 6.97 \\
\hline \multirow[t]{3}{*}{200} & 303 & 189 & 159.39 & 8.97E-02 & 0.82 & 23.43 & 194.86 & $5.24 \mathrm{E}-04$ & 0.89 & 14.11 \\
\hline & 313 & 190 & 159.38 & $1.59 \mathrm{E}+02$ & 0.80 & 24.28 & 65.88 & $1.71 \mathrm{E}-03$ & 0.76 & 1.65 \\
\hline & 323 & 190 & 166.21 & $9.24 \mathrm{E}-02$ & 0.84 & 20.72 & 202.98 & $5.19 \mathrm{E}-04$ & 0.91 & 11.64 \\
\hline \multirow[t]{3}{*}{300} & 303 & 285 & 260.13 & $1.25 \mathrm{E}-01$ & 0.92 & 6.77 & 297.90 & $5.52 \mathrm{E}-04$ & 0.96 & 4.84 \\
\hline & 313 & 286 & 271.60 & $1.12 \mathrm{E}-01$ & 0.96 & 4.90 & 314.06 & $4.60 \mathrm{E}-04$ & 0.98 & 3.35 \\
\hline & 323 & 286 & 277.84 & 1.37E-01 & 0.98 & 2.04 & 313.10 & $6.15 \mathrm{E}-04$ & 0.97 & 3.08 \\
\hline
\end{tabular}

which retards further diffusion and finally the adsorption rate itself gets changed.

\subsubsection{Adsorption thermodynamics}

In the interaction process design, energy and entropy are the chief factors to be considered. The extent of spontaneity of the adsorption process could be seen from standard Gibbs free energy change $\left(\Delta G^{\circ}\right)$. Significant adsorption occurs when the free energy change $\left(\Delta G^{\circ}\right)$ of adsorption is negative while, substantial adsorption takes place. Van't Hoff and Gibbs-Helmholtz equations provide the changes in adsorption of Gibbs free energy, entropy and enthalpy

$K_{L}=\frac{C_{a c}}{C_{e}}$

$\Delta G^{\circ}=-R T \ln K_{L}$

$\ln K_{L}=\Delta S^{\circ} /_{R}-\Delta H^{\circ} / R T$

$K_{L}$ represents equilibrium constant of thermodynamic $(\mathrm{I} / \mathrm{mol}) ; \mathrm{T}$ is temperature (K). $C_{a c}$ and $C_{e}$ indicate initial and equilibrium concentrations $(\mathrm{mg} / \mathrm{L})$ respectively of dye solution. $\Delta \mathrm{H}^{\circ}, \Delta \mathrm{S}^{\circ}$ and $\mathrm{E}_{\mathrm{a}}$ could be determined using the slope and intercept of Van't Hoff plots of $\ln \left(K_{d}\right)$ and $\ln \left(K_{2}\right)$ versus $1 / T$ respectively. They are shown in Fig. $9 a, b$.

Table 6 gives estimates of thermodynamic parameters. Positive $\Delta \mathrm{H}^{\circ}$ value indicates that the adsorption is endothermic whereas if $\Delta G^{\circ}$ values are negative then it implies that process of adsorption is feasible and spontaneous. In the present experiment $\Delta G^{\circ}$ is found to be negative at all temperatures. Hence the process of adsorption of AB113 dye by NITTS is almost spontaneous and is favorable. The decrease in $\Delta G^{\circ}$ value at higher temperatures is an indication for increased adsorption at higher temperatures. The $\Delta S^{\circ}$ has positive value which implies that $A B 113$ dye has good affinity towards NITTS and also the randomness at solid solution surface is higher. Very low values of $\Delta \mathrm{H}^{\circ}$ is the indication for the physical nature of the adsorption process since the prescribed value for enthalpy change in chemical reaction is usually $>200 \mathrm{~kJ} / \mathrm{mol}$. The activation energy values of the adsorption process at initial concentrations $(100,150$ and $200 \mathrm{ppm})$ have also confirmed this by having values ranging from -233.16 to $34.84 \mathrm{~kJ} / \mathrm{mol}$ as obtained by applying kinetic constant from pseudosecond order model and the Arrhenius equation.

\subsection{Statistical optimization by fractional factorial experimental design}

Experiments were carried out with different combinations of six independent variables to study their individual as well as combined effects. Analysis of variance (Table 7) obtained from the quadratic regression analysis clearly showed the significance of individual and combined effects of these factors. Significance of factors was considered at $p$ value $\leq 0.05$. In this study $A, C, E, F, A C, A^{2}, E^{2}$ and $F^{2}$ were significant model terms and other variables are insignificant. Cross products $A D, A E, B D, B E, B F, C D, C E, C F$ and DE were zero. The RSM model is highly significant with model F-value of 179.2. The predicted $R^{2}$ value of $84.70 \%$ is in reasonable agreement with the adjusted $R^{2}$ value of $94.50 \%$. High $R^{2}$ value of $95.10 \%$ and coefficient of variance of $14.10 \%$ assure that model can be used to navigate the design space. The comparison graph for actual versus predicted values Fig. 10a indicates a strong relation between the experimental and predicted responses. The regression equation obtained is shown below equation (Eq. 7)

$$
\begin{aligned}
\text { Adsorption }= & -61.8+59.7 * \mathrm{~A}+6.1 * \mathrm{~B}+216.6 * \mathrm{C} \\
& -4.0 * \mathrm{D}-99.7 * \mathrm{E}-73.2 * \mathrm{~F}-4.3 * \mathrm{AB} \\
& +22.9 * \mathrm{AC}+5.5 * \mathrm{BC}-79.1 * \mathrm{~A}^{2}+0.6 * \mathrm{~B}^{2} \\
& -7.7 * \mathrm{C}^{2}-1.9 * \mathrm{D}^{2}-112.5 * \mathrm{E}^{2}+105.0 * \mathrm{~F}^{2}
\end{aligned}
$$



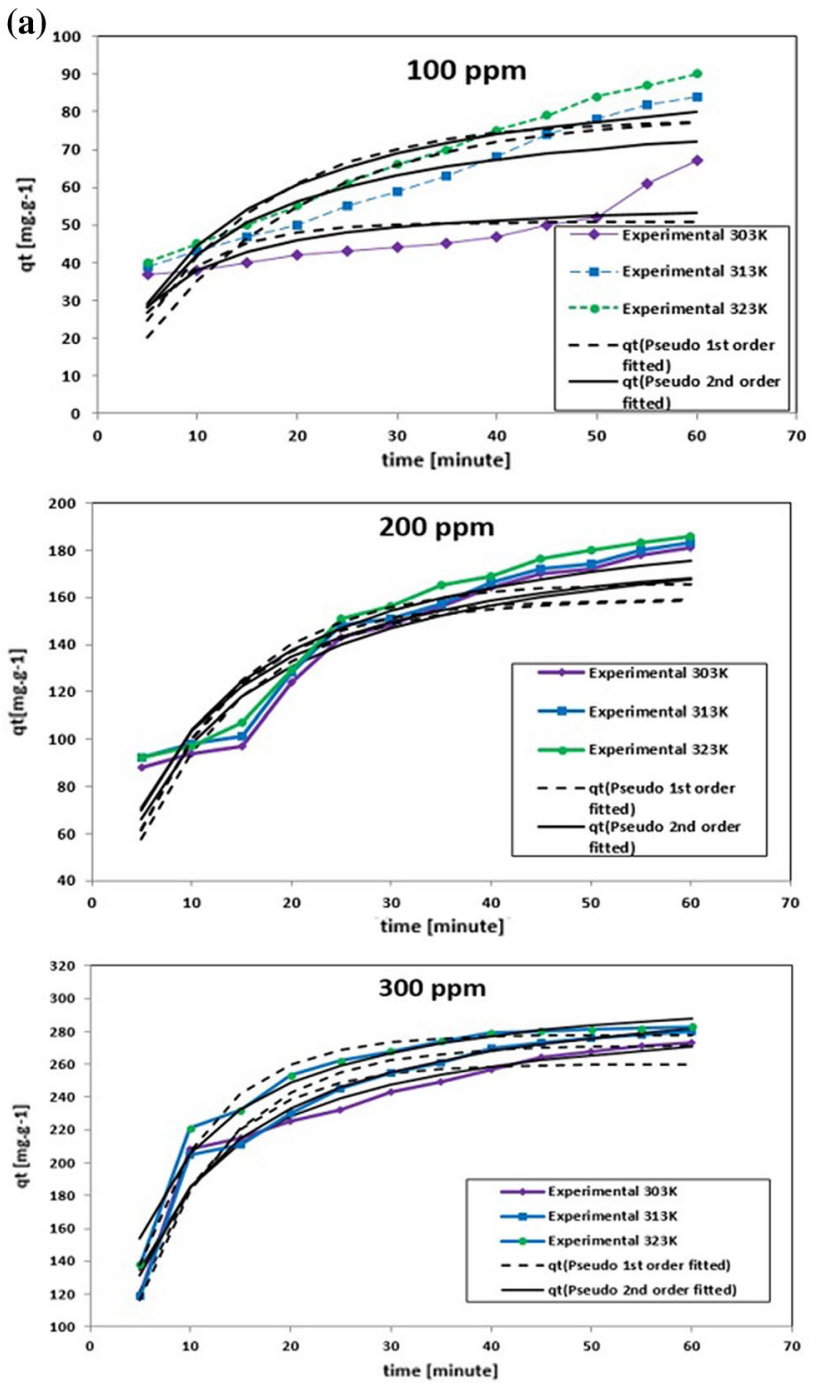

Fig. 8 a Kinetic model fits for 100 ppm initial concentration of $A B-113$ on TTS system at different temperatures, $\mathbf{b}$ kinetic model fits for $200 \mathrm{ppm}$ initial concentration of AB-113 on TTS system at different temperatures, c kinetic model fits for 300 ppm initial concentration of AB-113 on TTS system at different temperatures, d kinetics data fitted to the Dumwald-Wagner model with initial concentration of BG: A 50 ppm, B 100 ppm, C 150 ppm, e kinetics data fitted to the Weber-Morris model with initial concentration of BG: A 50 ppm, B 100 ppm, C 150 ppm, f kinetics data fitted to the film diffusion model with initial concentration of BG: A 50 ppm, B 100 ppm, C 150 ppm

The variables optimal values were arrived at by maximizing second-order polynomial equation with interaction terms, got from FFED based multiple regression analysis. Maximum adsorption value obtained by statistical optimization was $721 \mathrm{mg} / \mathrm{g}$ under optimized conditions which are $\mathrm{pH} 1$, adsorbent dosage $0.600 \mathrm{~g} / \mathrm{L}$, adsorbent particle size $448 \mu$, initial dye concentration $599 \mathrm{mg} / \mathrm{L}$ for adsorption time of 142 min with orbital shaking of $165 \mathrm{rpm}$ at $59^{\circ} \mathrm{C}$ temperature. Finally optimization was done by analysing $3 \mathrm{D}$
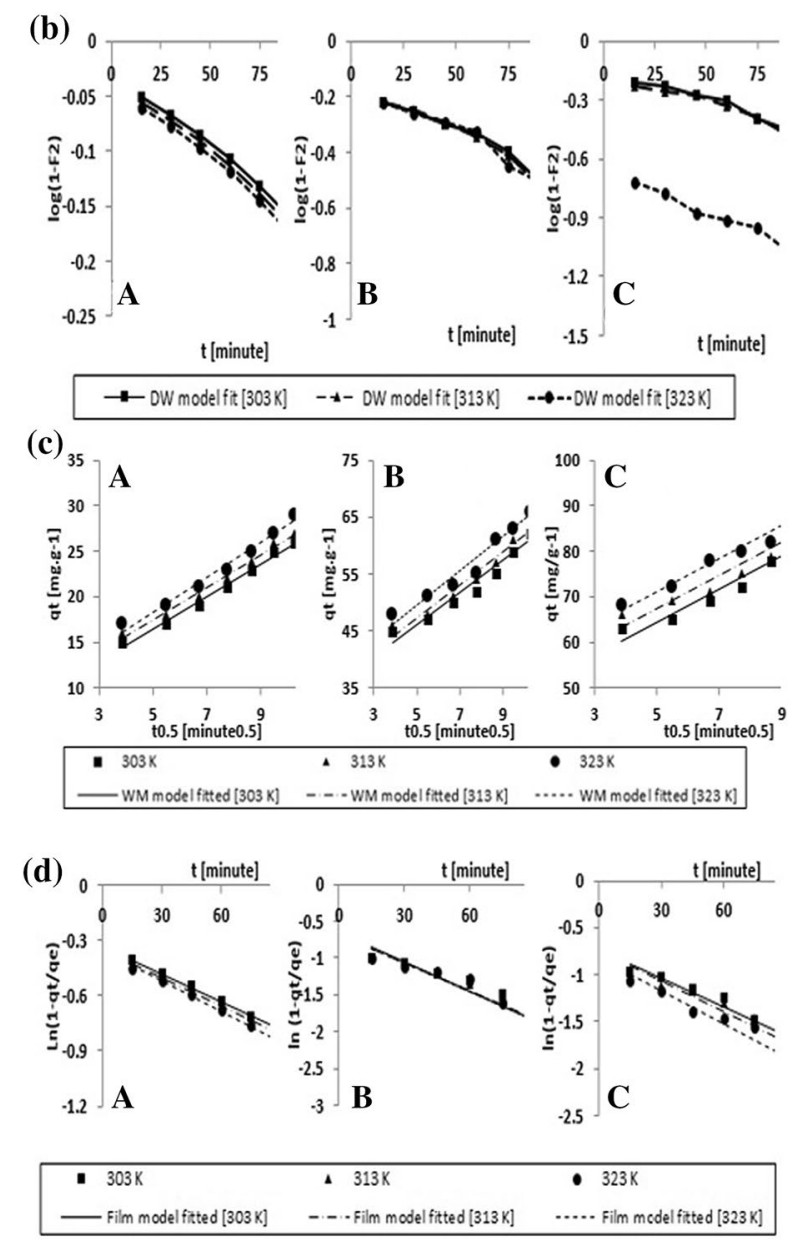

Fig. 8 (continued)

response surface plots as also contour plots as function of two independent variables. This helped to find the interaction between two parameters maintaining others at constant value.

By process optimization, the prescribed values for different parameters make it to arrive at optimal condition, and also it is possible to determine the influence of process conditions on adsorption. This can be done in the given range of parameter values. 3D graphs plotted for time against adsorbent dosage (AE), time against $\mathrm{pH}(\mathrm{AF})$ and adsorbent dosage against $\mathrm{pH}(\mathrm{EF})$ indicate that time has a positive effect on adsorption capacity Fig. 10b-d. By increasing time along with temperature and dye concentration, it is possible to increase the process of adsorption. Maximum time of 142 min has shown maximum adsorption. Absorbent dosage has negative effect on adsorption however increased time can improve the process of adsorption. Maximum $\mathrm{pH}$ for the increased adsorption capacity is around 11 and increasing in value has positive effect on the adsorption capacity along with increase in time. Time, adsorbent dosage and $\mathrm{pH}$ against other independent variables indicate that 
Table 5 Calculated parameters for diffusion models

\begin{tabular}{|c|c|c|c|c|c|c|c|}
\hline \multirow{2}{*}{$\begin{array}{l}\text { Initial concen- } \\
\text { tration } \\
\text { (ppm) }\end{array}$} & \multirow{2}{*}{$\begin{array}{l}\text { Temp } \\
(\mathrm{K})\end{array}$} & \multicolumn{2}{|c|}{ Film diffusion model } & \multicolumn{2}{|c|}{ Weber-Morris model } & \multicolumn{2}{|c|}{ Dumwald-Wagner } \\
\hline & & $R^{\mid}\left(\min ^{-1}\right)$ & $R^{2}$ & $k_{\text {ist }}\left(\mathrm{mg} / \mathrm{g} \mathrm{s}^{-0.5}\right)$ & $R^{2}$ & $K\left(\min ^{-1}\right)$ & $R^{2}$ \\
\hline \multirow[t]{3}{*}{100} & 303 & 0.0051 & 0.99 & 1.79 & 0.99 & 0.003 & 0.99 \\
\hline & 313 & 0.0051 & 0.99 & 1.79 & 0.99 & 0.003 & 0.99 \\
\hline & 323 & 0.0051 & 0.99 & 1.92 & 0.99 & 0.004 & 0.99 \\
\hline \multirow[t]{3}{*}{200} & 303 & 0.0127 & 0.96 & 2.88 & 0.96 & 0.012 & 0.92 \\
\hline & 313 & 0.0127 & 0.95 & 2.93 & 0.97 & 0.011 & 0.95 \\
\hline & 323 & 0.0127 & 0.93 & 3.05 & 0.96 & 0.012 & 0.94 \\
\hline \multirow[t]{3}{*}{300} & 303 & 0.0101 & 0.98 & 3.67 & 0.97 & 0.009 & 0.97 \\
\hline & 313 & 0.0109 & 0.96 & 3.68 & 0.95 & 0.009 & 0.95 \\
\hline & 323 & 0.0118 & 0.96 & 3.65 & 0.98 & 0.012 & 0.97 \\
\hline
\end{tabular}

Fig. 9 a Plot of thermodynamic equilibrium constant versus $1 / T$ to determine the enthalpy and Gibbs free energy of the process, $\mathbf{b}$ plot of pseudo-second order kinetic constant versus $1 / T$ to determine the activation energy of the process
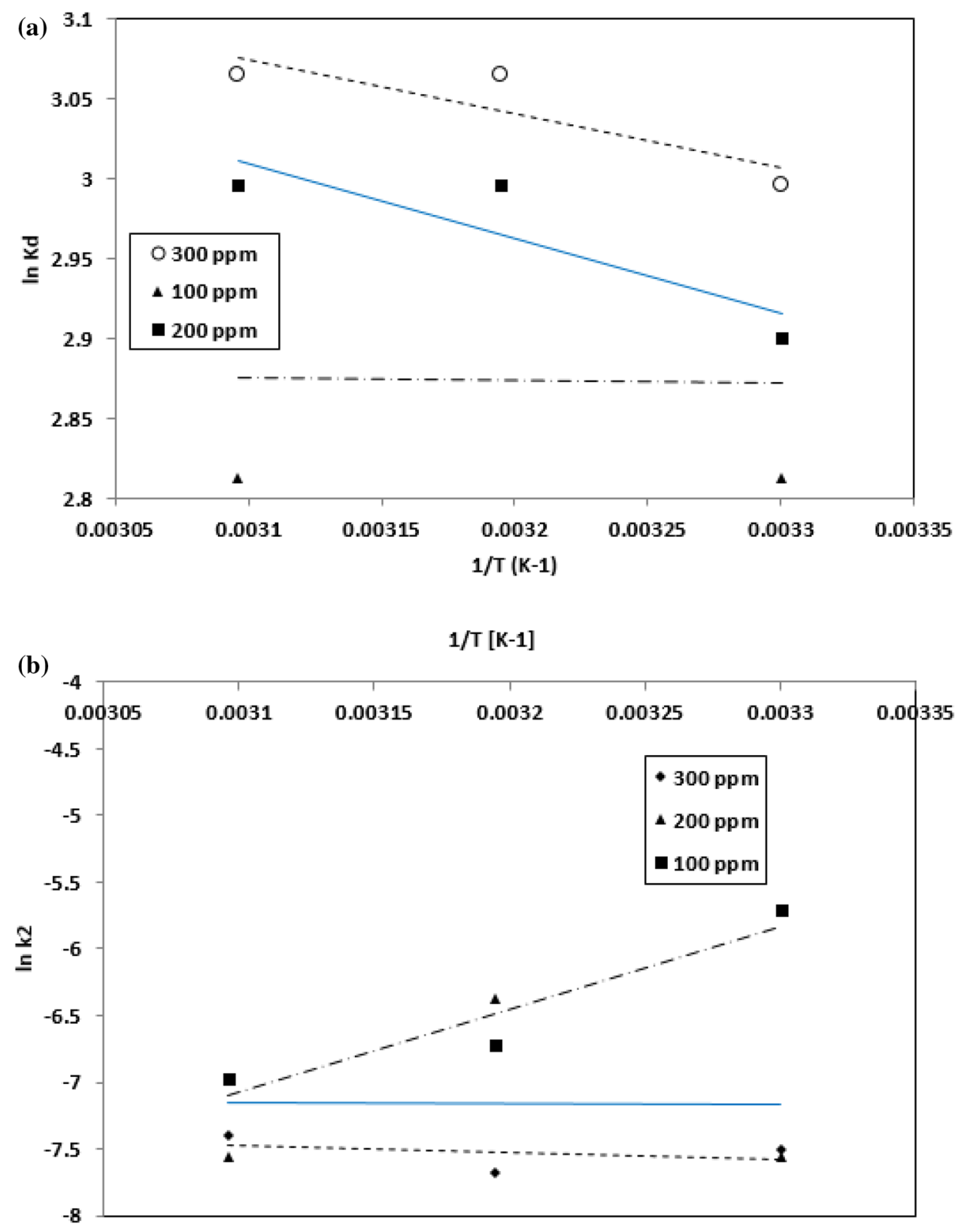
Table 6 Thermodynamic parameters of AB113-NITTS system

\begin{tabular}{lllllll}
\hline $\begin{array}{l}\text { Initial concen- } \\
\text { tration } \\
(\mathrm{ppm})\end{array}$ & $\begin{array}{l}\text { Temperature } \\
(\mathrm{K})\end{array}$ & $\Delta \mathrm{G}^{\circ}$ & $\Delta \mathrm{S}^{\circ}$ & $\Delta \mathrm{H}^{\circ}$ & $\ln \mathrm{A}$ & $\mathrm{E}_{\mathrm{a}}$ \\
\hline 300 & 303 & -7.55 & 34.36 & 2.84 & -5.92 & 4.19 \\
& 313 & -7.98 & & & & \\
& 323 & -8.23 & & & & \\
200 & 303 & -7.31 & 37.17 & 3.92 & -6.92 & 0.64 \\
& 313 & -7.80 & & & & \\
& 323 & -8.04 & & & & \\
100 & 303 & -7.09 & 24.40 & 0.16 & -26.44 & -51.92 \\
& 313 & -7.80 & & & & \\
& 323 & -7.56 & & & & \\
\hline
\end{tabular}

Table 7 ANOVA for fractional factorial experimental design

\begin{tabular}{|c|c|c|c|c|c|}
\hline Source & $\begin{array}{l}\text { Sum of } \\
\text { squares }\end{array}$ & $\begin{array}{l}\text { Degree } \\
\text { of free- } \\
\text { dom }\end{array}$ & $\begin{array}{l}\text { Mean } \\
\text { square }\end{array}$ & F value & $p$ value \\
\hline Model & 1182833.5 & 15 & 78855.6 & 179.2 & $<0.001^{* *}$ \\
\hline A & 101613.8 & 1 & 101613.8 & 230.9 & $<0.001^{* *}$ \\
\hline B & 1345.0 & 1 & 1345.0 & 3.1 & $0.0826^{+}$ \\
\hline C & 410892.0 & 1 & 410892.0 & 933.6 & $<0.001^{* *}$ \\
\hline D & 64.7 & 1 & 64.7 & 0.1 & 0.7021 \\
\hline$E$ & 41739.3 & 1 & 41739.3 & 94.8 & $<0.001^{* *}$ \\
\hline $\mathrm{F}$ & 25288.1 & 1 & 25288.1 & 57.5 & $<0.001^{* *}$ \\
\hline$A B$ & 507.0 & 1 & 507.0 & 1.2 & 0.2850 \\
\hline AC & 4006.6 & 1 & 4006.6 & 9.1 & $0.0030^{* *}$ \\
\hline$B C$ & 265.4 & 1 & 265.4 & 0.6 & 0.4388 \\
\hline$A^{2}$ & 74077.3 & 1 & 74077.3 & 168.3 & $<0.001^{* *}$ \\
\hline$B^{2}$ & 5.6 & 1 & 5.6 & 0.0 & 0.9106 \\
\hline$C^{2}$ & 181.7 & 1 & 181.7 & 0.4 & 0.5216 \\
\hline$D^{2}$ & 3.6 & 1 & 3.6 & 0.0 & 0.9285 \\
\hline$E^{2}$ & 14437.2 & 1 & 14437.2 & 32.8 & $<0.001^{* *}$ \\
\hline$F^{2}$ & 19664.4 & 1 & 19664.4 & 44.7 & $<0.001^{* *}$ \\
\hline Residual & 9643.4 & 120 & 80.4 & & \\
\hline Total & 235455.0 & 133 & & & \\
\hline
\end{tabular}

+ Suggestive significant ( $p$ value: $0.05<p<0.10$ )

*Moderately significant ( $p$ value: $0.01<p \leq 0.05$ )

**Strongly significant ( $p$ value: $p \leq 0.01$ )

the parameters $A, E$ and $F$ have positive effect with all other variables on the response. Thus, effect of two parameters together on the adsorption is graphically represented in the surface and contour plots Fig. 10b-d.

The quadratic model developed for process optimization is found to be beneficial for predicting the maximum adsorption capacity and understanding the interaction between independent variables as well as their independent effect on adsorption process. It is evident that by statistical optimization there is increase in adsorption from 190 to $350 \mathrm{mg} / \mathrm{g}$, which amounts to almost $84.20 \%$ increase.

\section{Application to textile industrial effluent}

Preliminary trial study revealed that better results could be obtained by scaling up to two-orders of the adsorbent and the adsorbate and to one order of the volume of the solution. In an interesting observation the Solution 2 showed about $20 \%$ decrease in absorbance compared to Solution 1. This may be due to the absorbance of the dye by varied undefined constituents present in TIE. Also, it was observed that additional fresh samples of the adsorbent after every 15 min enhanced the efficiency of removal of the dye from TIE. The recovery of the dye and allied substances from Solution 2 to an extent of 75, 90, 93 and $95 \%$ after 15, 30, 45 and 60 min respectively was observed. This observation is in line with the kinetic results, where the solute gets adsorbed onto the surface quickly forming a film. The adsorption later on gets retarded due to the film thereby causing change in absorption rates. The powder and filtrate solutions after the adsorption of constituents of Solution 2 on NITTS are shown in Fig. 11b, c.

\subsection{Scale up experiments up to three orders}

Scaling up of the experiment was done by using $10 \mathrm{~g}, 20 \mathrm{~g}$, and $50 \mathrm{~g}$ of NITTS and using 1,2 and $5 \mathrm{~L}$ of Solution 2 using polyethylene beakers. Solutions were stirred thoroughly using magnetic stirrer and the procedure as described earlier was repeated. Uniform results were obtained. Experiments were done in triplicate and the averages are reported. The coefficients of variation of results did not exceed in all cases $\pm 2 \%$ error.

The scale up experiments done to the extent of about three orders (restricted to adsorbent) compared to its initial set up has yielded promising results. The quantity and content of effluents from industry may vary so the results cannot be exactly predicted always from the initial data. Such limitation is a serious problem in such studies. In order to pin pointedly focus the results larger pilot scale 

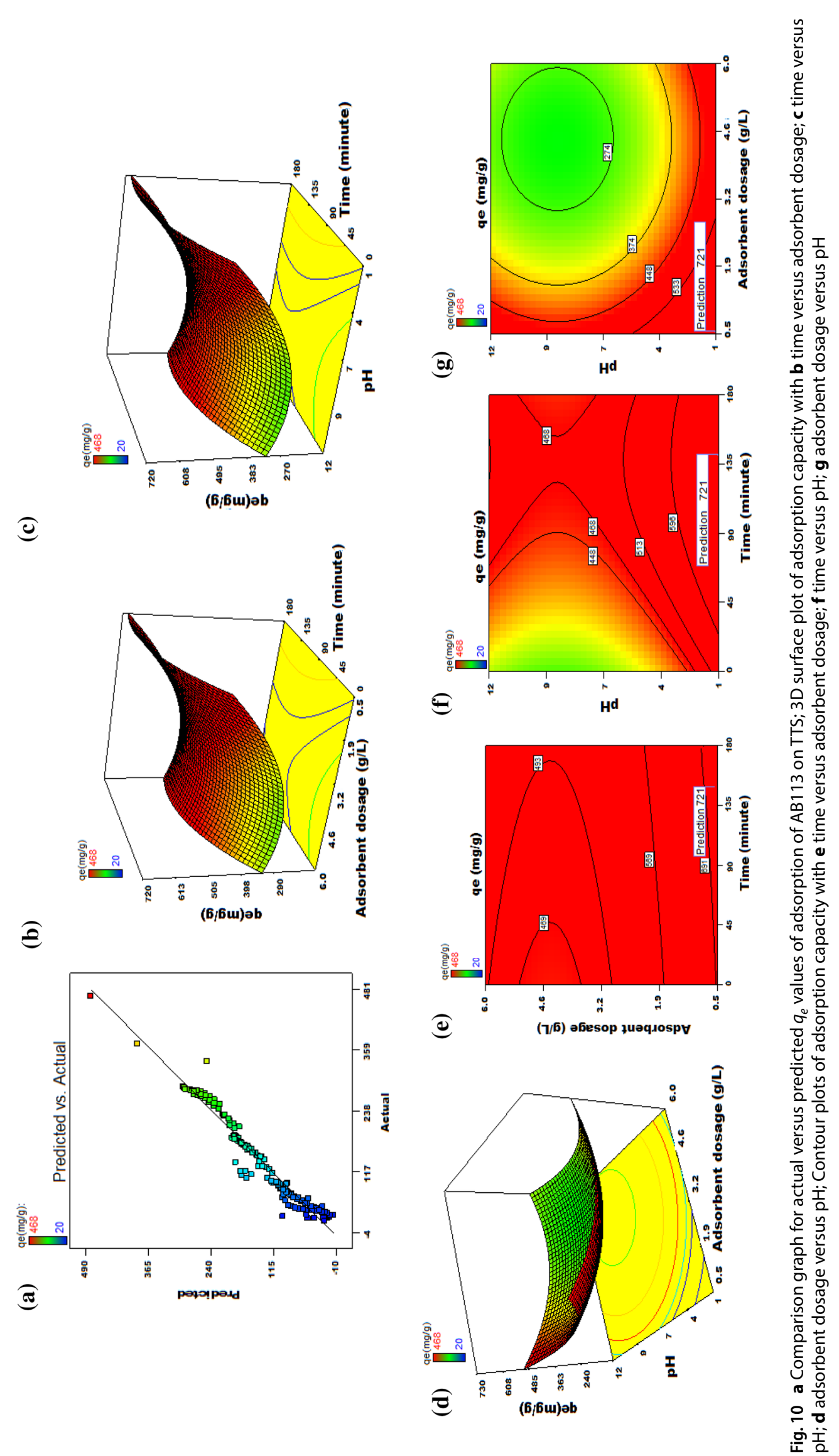

SN Applied Sciences

a SPRInger Nature journal 
Fig. 11 a Determination of molecular extinction coefficient of $A B 113$ dye, $\mathbf{b}$ powders 1 to 4 : fresh samples of NITTS added to AB113-TIE solution after every $15 \mathrm{~min}$, filtered and the residue dried in oven. Sample 5: NITTS, c colour of the solutions before and after adsorption: 1. Distilled water; 2. AB113 in distilled water; 3. TIE; 4. AB113 in TIE; 5. Filtrate after adsorption of dye on NITTS after $15 \mathrm{~min} ; 6.30 \mathrm{~min} ; 7$ $45 \mathrm{~min} ; 8.60 \mathrm{~min}$; 9. Filtrate of NITTS in distilled water (a)

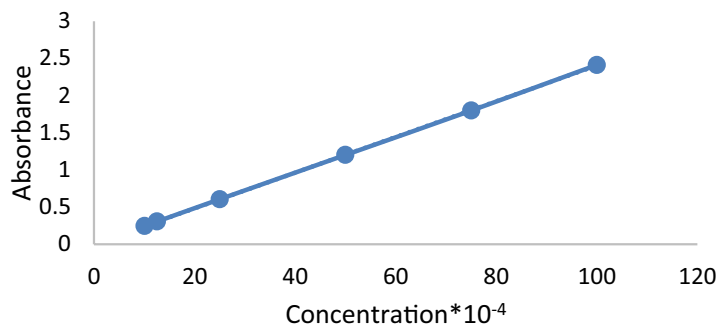

(b)

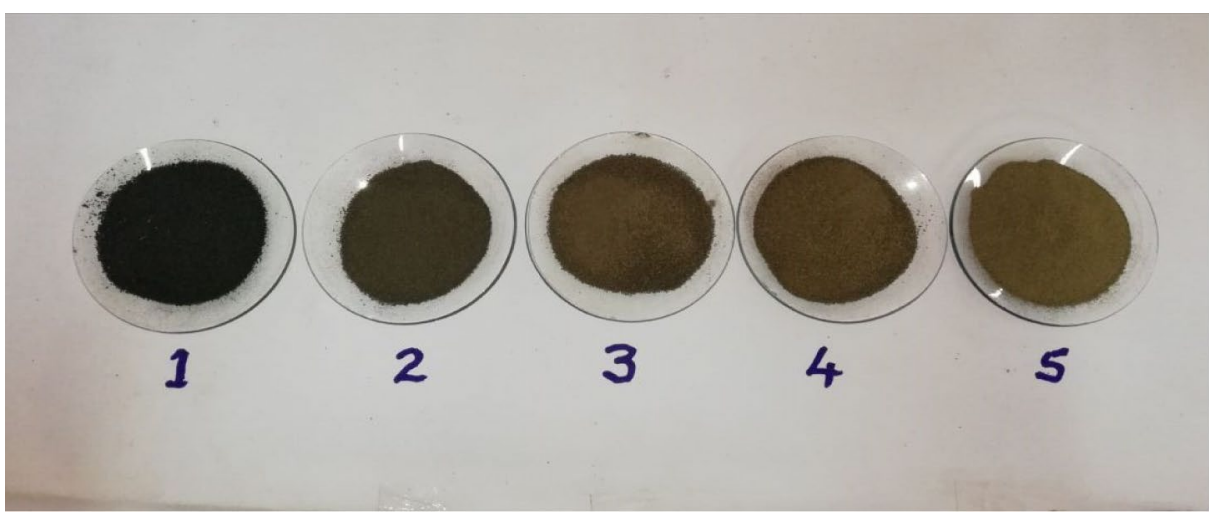

(c)

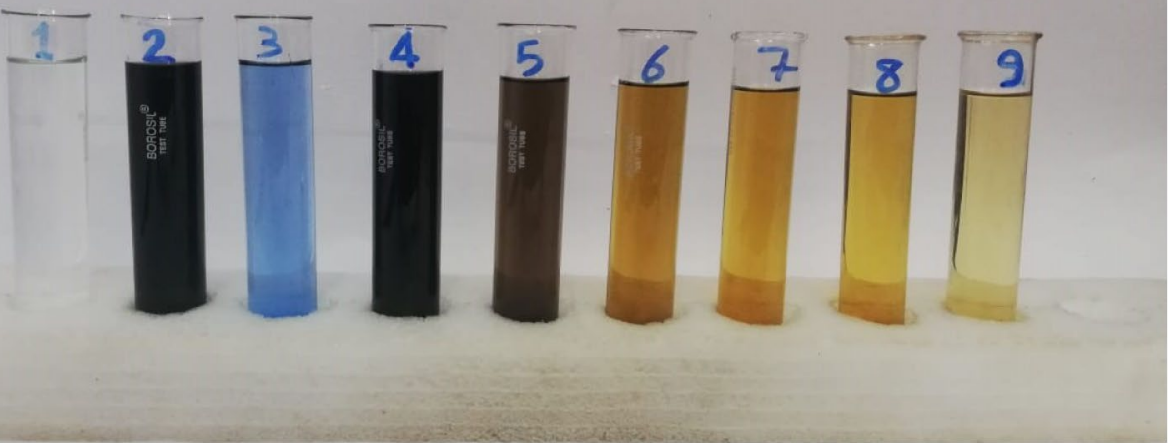

studies are necessary. However, the enhanced scale experimental data will certainly yield promising reliability about the process, and it will definitely prove the principles of the method when subjected for development on a bigger scale in industrial environment.

\subsection{Regeneration of the adsorbent and cost analysis}

Regeneration of dye-loaded NITTS enables its re-use and recovery of the adsorbed material. Regeneration of NITTS is not advisible since the process cost along with the cost of solvents will be very higher as compared to the sorbents cost alone used in the process. In addition we should also consider the enhancement of E-factor [41] which is not affordable as the planet is not in a position to bear increased load of environmental toxicants. The better approach for the disposal of the waste process materials could be to use the current method which is under development which is to fabricate thermosets and thermoplastics. Work on which is in progress in our laboratory and some interesting results obtained are reported elsewhere $[64,65]$.

\section{Conclusion}

The present investigation has shown that Nutraceutical Industrial T. terrestris Seed Spent can be used successfully as in an effective adsorbent in removing $A B 113$ from aqueous solution. $A B 113$ adsorption process by NITTS involved is purely endothermic and almost spontaneous. Pseudo-second-order kinetic model fits with the present results. The film shows substantial effect on intraparticular diffusion. The process is mainly of physical one 
as evidenced by low value of $\Delta \mathrm{H}$. The adsorption of $\mathrm{AB} 113$ by NITTS is confirmed by looking at the SEM images and FTIR spectra.

Utilization of NIS and dye adsorbed NIS can alleviate waste disposal problems in the landfills caused by nutraceutical and textile industries and likely to create jobs for fabricating composites. Also, opens up new route to cleaner, cheaper, and efficient technology based on a new class of adsorbents-Nutraceutical Industrial Spent.

Acknowledgements One of the authors (MAHDA) gratefully acknowledges Thamar University, Republic of Yemen for the award of Overseas Research Fellowship.

\section{Compliance with ethical standards}

Conflict of interest All authors declare no conflict of interest.

\section{References}

1. Alkan M, Demirbaş Ö, Doğan M (2007) Adsorption kinetics and thermodynamics of an anionic dye onto sepiolite. Microporous Mesoporous Mater 101(3):388-396

2. APHA (2005) Standard methods for the examination of water and waste water, 21 st edn. American Public Health Association, Washington

3. Bafana A, Devi SS, Chakrabarti T (2011) Azo dyes: past, present and the future. Environ Rev 19:350-371

4. Boyd GE, Adamson AW, Myers LS Jr (1947) The exchange adsorption of ions from aqueous solutions by organic zeolites. II. Kinetics. J Am Chem Soc 69(11):2836-2848

5. Boulinguiez B, Le Cloirec P, Wolbert D (2008) Revisiting the determination of Langmuir parameters application to tetrahydrothiophene adsorption onto activated carbon. Langmuir 24(13):6420-6424

6. Brouers F, Sotolongo O, Marquez F, Pirard JP (2005) Microporous and heterogeneous surface adsorption isotherms arising from levy distributions. Physica A Stat Mech Appl 349(1):271-282

7. Bulut $E$, Özacar M, Şengil IA (2008) Adsorption of malachite green onto bentonite: equilibrium and kinetic studies and process design. Microporous Mesoporous Mater 115(3):234-246

8. Cardenas PAM, Ibanez JG, Vasquez MR (2012) Determination of the point of zero charge for electrocoagulation precipitates from an iron anode. Int J Electrochem Sci 7:6142-6153

9. Chhatre S, Nesari T, Somani G, Kanchan D, Sathaye S (2014) Phytopharmacological overview of Tribulus terrestris. Pharmacogn Rev 8(15):45-51

10. Chowdhury S, Das P (2012) Utilization of a domestic wasteeggshells for removal of hazardous malachite green from aqueous solutions. Environ Prog Sustain Energy 31(3):415-425

11. Dávila-Jiménez MM, Elizalde-González MP, Peláez-Cid AA (2005) Adsorption interaction between natural adsorbents and textile dyes in aqueous solution. Colloids Surf A 254(1-3):107-114

12. Duke JA (2002) Handbook of medicinal herbs, 2nd edn. CRC Press, Boca Raton, p 595

13. Eskandarian M, Mahdizadeh F, Ghalamchi L, Naghavi S (2014) Bio-Fenton process for acid blue 113 textile azo dye decolorization: characteristics and neural network modeling. Desalin Water Treat 52(25-27):4990-4998
14. Freundlich HMF (1906) Over the adsorption in solution. J Phys Chem 57:385-471

15. Ghiaci M, Abbaspur A, Kia R, Seyedeyn-Azad F (2004) Equilibrium isotherm studies for the sorption of benzene, toluene, and phenol onto organo-zeolites and as-synthesized MCM-41. Sep Purif Technol 40(3):217-229

16. Gupta VK, Gupta B, Rastogi A, Agarwal S, Nayak A (2011) A comparative investigation on adsorption performances of mesoporous activated carbon prepared from waste rubber tire and activated carbon for a hazardous azo dye-acid blue 113 . J Hazard Mater 186(1):891-901

17. Ho YS, McKay G (1998) Sorption of dye from aqueous solution by peat. Chem Eng J 70(2):115-124

18. https://www.ibef.org/industry/textiles.aspx. Accessed $28 \mathrm{Mar}$ 2018

19. https://www.worldatlas.com/articles/the-top-10-pollutingindustries-in-the-world.html. Accessed 19 Nov 2018

20. Husain Q, Karim Z, Banday ZZ (2010) Decolorization of textile effluent by soluble fenugreek (Trigonella foenum-graecum L.) seeds peroxidase. Water Air Soil Pollut 212(1-4):319-328

21. Khehra MS, Saini HS, Sharma DK, Chadha BS, Chimni SS (2005) Comparative studies on potential of consortium and constituent pure bacterial isolates to decolorize azo dyes. Water Res 39(20):5135-5141

22. Kumar KV (2006) Comparative analysis of linear and non-linear method of estimating the sorption isotherm parameters for malachite green onto activated carbon. J Hazard Mater 136(2):197-202

23. Kumar P, Prasad B, Mishra IM, Chand S (2007) Catalytic thermal treatment of desizing wastewaters. J Hazard Mater 149(1):26-34

24. Kumar KV, Sivanesan S (2007) Sorption isotherm for safranin onto rice husk: comparison of linear and non-linear methods. Dyes Pigments 72(1):130-133

25. Lagergren S (1898) About the theory of so-called adsorption of soluble substances. Kungliga Svenska Vetenskapsakademiens Handlingar 24:1-39

26. Langmuir I (1916) The constitution and fundamental properties of solids and liquids. J Am Chem Soc 38(11):2221-2295

27. Lataye DH, Mishra IM, Mall ID (2008) Adsorption of 2-picoline onto bagasse fly ash from aqueous solution. Chem Eng J 138(1-3):35-46

28. Lee LY, Chin DZB, Lee XJ, Chemmangattuvalappil N, Gan S (2015) Evaluation of abelmoschus esculentus (lady's finger) seed as a novel biosorbent for the removal of acid blue 113 dye from aqueous solutions. Process Safe Environ 94:329-338

29. Malek A, Farooq S (1996) Comparison of isotherm models for hydrocarbon adsorption on activated carbon. AIChE J 42(11):3191-3201

30. Nadkarni KM (1927) Indian materia medica. Mumbai Popular Prakashan 1230-1231

31. Ncibi MC (2008) Applicability of some statistical tools to predict optimum adsorption isotherm after linear and non-linear regression analysis. J Hazard Mater 153(1-2):207-212

32. Papegowda PK, Syed AA (2017) Isotherm, kinetic and thermodynamic studies on the removal of methylene blue dye from aqueous solution using Saw Palmetto spent. Int J Environ Res 11(1):91-98

33. Pashaei S, Siddaramaiah Syed AA (2011) Investigation on mechanical, thermal and morphological behaviors of turmeric spent incorporated vinyl ester green composites. Polym Plast Technol Eng 50(12):1187-1198

34. Pura S, Atun G (2009) Adsorptive removal of acid blue 113 and tartrazine by fly ash from single and binary dye solutions. Sep Sci Technol 44(1):75-101

35. Radke CJ, Prausnitz JM (1972) Thermodynamics of multi-solute adsorption from dilute liquid solutions. Alche J 18(4):761-768 
36. Rai CL, Raghav M, Surianarayanan M, Sreenivas V (2013) Kinetic modelling on $\mathrm{Cl}$ acid blue-113 dye degradation by acoustic and hydrodynamic cavitations. Int J Environ Eng 5(2):208-227

37. Redlich OJDL, Peterson DL (1959) A useful adsorption isotherm. J Phys Chem 63(6):1024

38. Robinson T, McMullan G, Marchant R, Nigam P (2001) Remediation of dyes in textile effluent: a critical review on current treatment technologies with a proposed alternative. Bioresour Technol 77(3):247-255

39. Saravanan M, Sambhamurthy NP, Sivarajan M (2010) Treatment of acid blue 113 dye solution using iron electrocoagulation. Clean Soil Air Water 38(5-6):565-571

40. Sathishkumar P, Mangalaraja RV, Rozas O, Mansilla HD, GraciaPinilla MA, Anandan S (2014) Low frequency ultrasound (42 kHz) assisted degradation of acid blue 113 in the presence of visible light driven rare earth nanoclusters loaded $\mathrm{TiO}_{2}$ nanophotocatalysts. Ultrason Sonochem 21(5):1675-1681

41. Sheldon RA (1992) Organic synthesis-past, present and future. Chem Ind 23:903-906

42. Shirzad-Siboni M, Jafari SJ, Giahi O, Kim I, Lee SM, Yang JK (2014) Removal of acid blue 113 and reactive black 5 dye from aqueous solutions by activated red mud. J Ind Eng Chem 20(4):1432-1437

43. Shokohi R, Jafari SJ, Siboni M, Gamar N, Saidi S (2011) Removal of acid blue 113 (AB113) dye from aqueous solution by adsorption onto activated red mud: a kinetic and equilibrium study. Sci J Kurdistan Univ Med Sci 16(2):55-65

44. Shu HY, Chang MC, Fan HJ (2005) Effects of gap size and UV dosage on decolorization of $\mathrm{Cl}$ acid blue 113 wastewater in the UV/ $\mathrm{H}_{2} \mathrm{O}_{2}$ process. J Hazard Mater 118(1-3):205-211

45. Shu HY, Chang MC, Chen CC, Chen PE (2010) Using resin supported nano zero-valent iron particles for decoloration of acid blue 113 azo dye solution. J Hazard Mater 184(1-3):499-505

46. Shu HY, Chang MC, Huang SW (2015) UV irradiation catalyzed persulfate advanced oxidation process for decolorization of acid blue 113 wastewater. Desalin Water Treat 54(4-5):1013-1021

47. Shu HY, Huang SW, Tsai MK (2016) Comparative study of acid blue 113 wastewater degradation and mineralization by UV/ persulfate and UV/Oxone processes. Desalin Water Treat 57(60):29517-29530

48. Shu HY, Chang MC, Huang SW (2016) Decolorization and mineralization of azo dye acid blue 113 by the UV/Oxone process and optimization of operating parameters. Desalin Water Treat 57(17):7951-7962

49. Shu HY, Chang MC, Liu JJ (2016) Reductive decolorization of acid blue 113 azo dye by nanoscale zero-valent iron and iron-based bimetallic particles. Desalin Water Treat 57(17):7963-7975

50. Sips R (1948) Combined form of langmuir and freundlich equations. J Chem Phy 16(429):490-495

51. Srinivasan R, Mishra A (2008) Okra (Hibiscus esculentus) and fenugreek (Trigonella foenum graceum) mucilage: characterization and application as flocculants for textile effluent treatments. Chin J Polym Sci 26(06):679-687

52. Standard methods for the examination of water and wastewater 20th edn. American Public Health Association, Washington (2002)

53. Sulthana R, Taqui SN, Zameer F, Taqui SU, Syed AA (2018) Adsorption of ethidium bromide from aqueous solution on to nutraceutical industrial fennel seed spent: kinetics and thermodynamics modeling Studies. Int J Phytoremediation 20(11):1075-1086

54. Syed MA, Siddaramaiah Suresha B, Syed AA (2009) Mechanical and abrasive wear behavior of coleus spent filled unsaturated polyester/polymethyl methacrylate semi interpenetrating polymer network composites. J Compos Mater 43(21):2387-2400

55. Syed MA, Ramaraj B, Akhtar S, Syed AA (2010) Development of environmentally friendly high density polyethylene and turmeric spent composites: physicomechanical, thermal, and morphological studies. J Appl Polym Sci 118(2):1204-1210

56. Syed MA, Siddaramaiah Syed RT, Syed AA (2010) Investigation on physico mechanical properties, water, thermal and chemical ageing of unsaturated polyester/turmeric spent composites. Polym Plast Technol Eng 49(6):555-559

57. Syed MA, Akhtar S, Syed AA (2011) Studies on the physicomechanical, thermal and morphological behaviors of high density polyethylene/coleus spent green composites. J Appl Polym Sci 119(4):1889-1895

58. Syed MA, Syed AA (2012) Development of a new inexpensive green thermoplastic composite and evaluation of its physicomechanical and wear properties. Mater Des 36:421-427

59. Syed MA, Syed AA (2016) Development of green thermoplastic composites from Centella spent and study of its physicomechanical, tribological, and morphological Characteristics. J Thermoplast Compos Mater 29(9):1297-1311

60. Syed MA, Syed AA (2016) Investigation on physicomechanical and wear properties of new green thermoplastic composites. Polym Compos 37(8):2306-2312

61. Szyguła A, Guibal E, Ruiz M, Sastre AM (2008) The removal of sulphonated azo-dyes by coagulation with chitosan. Colloids Surf A 330(2-3):219-226

62. Talarposhti AM, Donnelly T, Anderson GK (2001) Colour removal from a simulated dye wastewater using a two-phase anaerobic packed bed reactor. Water Res 35(2):425-432

63. Talwar K, Kini S, Balakrishna K, Murty VRC (2016) Statistical analysis of acid blue-113 dye removal using palm tree male flower activated carbon. Int J Appl Environ Sci 11(2):475-490

64. Taqui SN, Yahya R, Hassan A, Nayak N, Syed AA (2017) Development of sustainable dye adsorption system using nutraceutical industrial fennel seed spent-studies using congo red dye. Int J Phytoremediat 19(7):686-694

65. Taqui SN, Yahya R, Hassan A, Nayak N, Syed AA (2018) A novel sustainable design to develop polypropylene and unsaturated polyester resin polymer composites from waste of major polluting industries and investigation on their physicomechanical and wear properties. Polym Compos. https://doi.org/10.1002/ pc. 24819

66. Thejaswini TV, Prabhakaran D (2016) Synthesis of mesoporous titania-silica monolith composites-a comprehensive study on their photocatalytic degradation of acid blue 113 dye under UV light. Int J Nanosci 15(05n06):1660012-1660020

67. Trease GE, Evans WC (2002) A taxonomic approach to the study of medicinal plants and animal derived drugs. In: Trease and evans pharmacognosy, 15th edn. Singapore, p 27

68. Toth J (1971) State equation of the solid-gas interface layers. Acta Chim Hung 69:311-328

69. Unnithan MR, Anirudhan TS (2001) The kinetics and thermodynamics of sorption of chromium (VI) onto the iron (III) complex of a carboxylated polyacrylamide-grafted sawdust. Ind Eng Chem Res 40(12):2693-2701

70. Vieth WR, Sladek KJ (1965) A model for diffusion in a glassy polymer. J Colloid Sci 20(9):1014-1033

71. Wang HL, Chen JL, Zhai ZC (2004) Study on thermodynamics and kinetics of adsorption of $p$-toluidine from aqueous solution by hypercrosslinked polymeric adsorbents. Environ Chem 23(2):188-192

72. Webber TW, Chakkravorti RK (1974) Pore and solid diffusion models for fixed-bed adsorbers. Alche J 20(2):228-238

73. Zaffalon V (2010) Carbon mitigation and textiles. Text World 160:35

74. Zayani G, Bousselmi L, Pichat P, Mhenni F, Ghrabi A (2008) Photocatalytic degradation of the acid blue 113 textile azo dye in aqueous suspensions of four commercialized $\mathrm{TiO}_{2}$ samples. $J$ Environ Sci Heal A 43(2):202-209 